\title{
Synoptic fluctuation of the Taiwan Warm Current in winter on the East China Sea shelf
}

\author{
Jiliang Xuan ${ }^{1}$, Daji Huang ${ }^{1,2}$, Thomas Pohlmann ${ }^{3}$, Jian Su ${ }^{3}$, Bernhard Mayer ${ }^{3}$, Ruibin Ding ${ }^{2,1}$, and Feng Zhou ${ }^{1,2}$ \\ ${ }^{1}$ State Key Laboratory of Satellite Ocean Environment Dynamics, Second Institute of Oceanography, State Oceanic \\ Administration, Hangzhou, China \\ ${ }^{2}$ Ocean College, Zhejiang University, Zhoushan, China \\ ${ }^{3}$ Institute of Oceanography, University of Hamburg, Hamburg, Germany \\ Correspondence to: Jiliang Xuan (xuanjl@sio.org.cn) and Daji Huang (djhuang@sio.org.cn)
}

Received: 28 August 2016 - Discussion started: 23 September 2016

Revised: 1 January 2017 - Accepted: 10 January 2017 - Published: 10 February 2017

\begin{abstract}
The seasonal mean and synoptic fluctuation of the wintertime Taiwan Warm Current (TWC) were investigated using a well-validated finite volume community ocean model. The spatial distribution and dynamics of the synoptic fluctuation were highlighted. The seasonal mean of the wintertime TWC has two branches: an inshore branch between the 30 and $100 \mathrm{~m}$ isobaths and an offshore branch between the 100 and $200 \mathrm{~m}$ isobaths. The Coriolis term is much larger than the inertia term and is almost balanced by the pressure gradient term in both branches, indicating geostrophic balance of the mean current. Two areas with significant fluctuations of the TWC were identified during wintertime. One of the areas is located to the north of Taiwan with velocities varying in the cross-shore direction. These significant crossshore fluctuations are driven by barotropic pressure gradients associated with the intrusion of the Taiwan Strait Current (TSC). When a strong TSC intrudes to the north of Taiwan, the isobaric slope tilts downward from south to north, leading to a cross-shore current from the coastal area to the offshore area. When the TSC intrusion is weak, the crossshore current to the north of Taiwan is directed from offshore to inshore. The other area of significant fluctuation is located in the inshore area between the 30 and $100 \mathrm{~m}$ isobaths. The fluctuations are generally strong both in the alongshore and cross-shore directions, in particular at the latitudes 26.5 and $28^{\circ} \mathrm{N}$. Wind affects the synoptic fluctuation through episodic events. When the northeasterly monsoon prevails, the southwestward Zhe-Min coastal current dominates the inshore area associated with a deepening of the mixed layer. When the winter monsoon is weakened or the southwesterly
\end{abstract}

wind prevails, the northeastward TWC dominates in the inshore area.

\section{Introduction}

On the East China Sea (ECS) shelf, the mean path of the Taiwan Warm Current (TWC) has two branches: the inshore branch along the $50 \mathrm{~m}$ isobath and the offshore branch along the $100 \mathrm{~m}$ isobath ( $\mathrm{Su}$ and Pan, 1987). The summer TWC has been well studied because the current is stationary and strong, with an average speed of $0.3 \mathrm{~m} \mathrm{~s}^{-1}$ (Guan, 1978; Fang et al., 1991; Isobe, 2008; Yang et al., 2011, 2012). The spatial structure and temporal variation of the wintertime (December to March) TWC are less known due to its weak mean surface velocity, according to a climatological structure of the surface current in the ECS mapped by Qiu and Imasato (1990).

The wintertime TWC on the ECS shelf shows synoptic fluctuations (Cui et al., 2004; Zhu et al., 2004; Zeng et al., 2012; Huang et al., 2016). These synoptic fluctuations show some features common to those over other continental shelves; i.e., they have periods between 3 and 15 days and are associated with coastal sea level changes, which can be explained by local winds or by coastal trapped waves (Huyer, 1990; Brink, 1991; Huthnance et al., 1986). Huang et al. (2016) showed that the wind was a main physical factor, which caused the temporal variation of the wintertime currents at the synoptic scale in the coastal area of the ECS. However, the dominant physical factors of the TWC fluctu- 

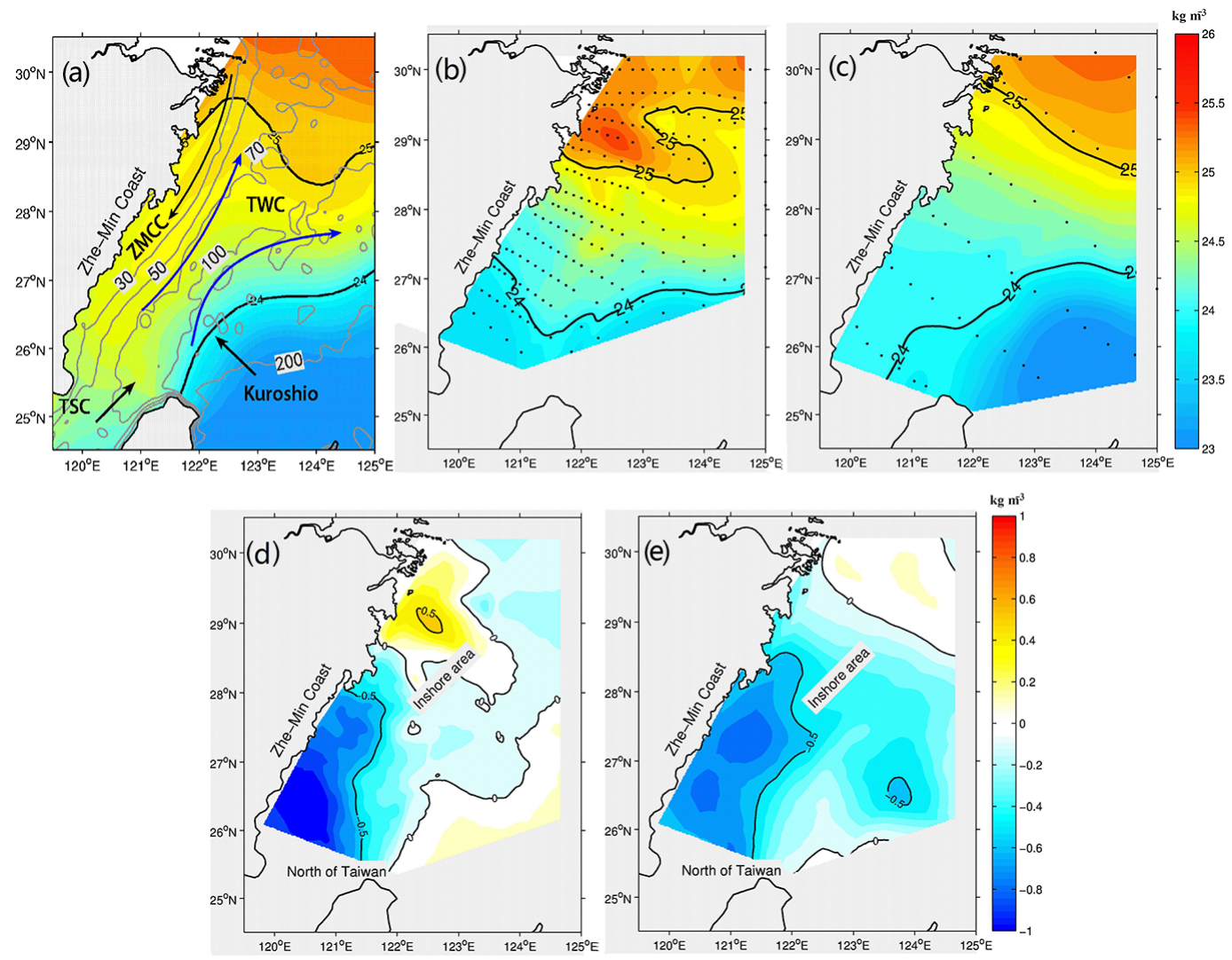

Figure 1. Density $\left(\sigma_{t}, \mathrm{~kg} \mathrm{~m}^{3}\right)$ distributions at $50 \mathrm{~m}$ depth derived from the GDEM climatological data in February (a), an ocean survey from 1 to 27 February 2007 (b), an ocean survey from 3 to 16 February 2007 (c) and the density anomalies between the GDEM data and the two surveys (d, e). The two blue arrows indicate the two TWC branches in winter. The 30, 50, 70, 100 and $200 \mathrm{~m}$ isobaths are indicated with gray lines in (a).

ations still lack study; the fluctuations on the whole shelf of the ECS may be complicated due to the complex bottom topography, alternating wind forcing and conjunction of several current systems such as the Kuroshio Current, the Taiwan Strait Current (TSC) and the Zhe-Min Coastal Current (ZMCC). These synoptic fluctuations are also known to influence the regional material transport, especially when the amplitude of the fluctuations is comparable to, or even larger than, the mean current. On the ECS shelf, some recent observations have shown that the TWC has an episodic wintertime feature (Zhu et al., 2004) and the variations of the TWC in winter have an amplitude as large as $0.2 \mathrm{~m} \mathrm{~s}^{-1}$ (Zeng et al., 2012). Moreover, it has been observed that the variations of the TWC in winter cause a cross-shore current, which is closely linked to the alongshore component (Huang et al., 2016). Therefore, we focus on studying the spatial patterns of synoptic fluctuations to better understand the role of the wintertime TWC on the cross-shore water exchange.

A comparison between the wintertime climatological density (Fig. 1a) and synoptic density distributions observed during two surveys (Fig. 1b and c) suggests that two distinct areas with significant synoptic fluctuations exist. The clima- tological density is taken from the Generalized Digital Environment Model (GDEM; Carnes, 2009) data, and the two surveys were carried out in February 2007 by two research vessels. Because the isopycnal lines are closely related to geostrophic currents, we can infer the strength of the TWC from the horizontal gradient of the isopycnals between $24 \sigma_{t}$ and $25 \sigma_{t}$ contours (Fig. 1a). This accounts for the fact that in winter the water mass of TWC is located in this density range (according to the hydrography analysis of $\mathrm{Su}$ et al., 1994). The two-branch structure of the TWC can be inferred from the wintertime climatological density. In this paper, we defined that the near-coast area is the area between the coast and $30 \mathrm{~m}$ isobath where the ZMCC occurs, the inshore area is the area between the 30 and $100 \mathrm{~m}$ isobaths where the TWC inshore branch dominates and the offshore area is the region between the 100 and $200 \mathrm{~m}$ isobaths where the TWC offshore branch prevails. According to the hydrographic data analysis and numerical interpretation by Su and Pan (1987), the TWC inshore and offshore branches mainly occur close to those specific isobaths. However, these two branches were missing during the two synoptic surveys (Fig. $1 \mathrm{~b}$ and c), indicating strong synoptic fluctuations of the TWC on the ECS shelf. 
Furthermore, the density anomalies between the two surveys and the GDEM data (Fig. 1d and e) indicate that the most significant fluctuations are located north of Taiwan and in the inshore area. Both surveys show negative density anomalies north of Taiwan, indicating that the TWC was weak and that more low-density coastal water was transported to the ECS shelf during the observational periods. The density anomalies in the inshore area show different patterns for the two synoptic surveys, with a positive anomaly in the first survey (Fig. 1d) and a negative anomaly in the second (Fig. 1e), indicating a strong synoptic fluctuation in the inshore area.

Candidate factors for driving these synoptic fluctuations are local wind, surface cooling, and the upstream currents of the Kuroshio Current and the TSC. As discussed by Huyer (1990), wind is often considered as the major driving mechanism of synoptic fluctuations of the wintertime TWC. The northeasterly monsoon wind in winter blows against the northeastward TWC and produces a southwestward ZMCC (Chuang and Liang, 1994; Oey et al., 2010). Zhu et al. (2004) suggested that the occurrence and duration of the TWC are associated with the meandering of the Kuroshio Current north of Taiwan. The northeastward TSC, as an upstream flow of the TWC, also influences the synoptic fluctuation of the wintertime TWC. Hong et al. (2011) and Hu et al. (2010) summarized that the temporal and spatial variation of TSC is modulated by strong wind forcing, complex topography and circulation in the northern South China Sea as well as coastal water input and the Kuroshio intrusion. Guan and Fang (2006) showed evidence that the TSC and the TWC merge in the area between the Taiwan Strait and the ZheMin coastal region. Takahashi and Morimoto (2013) pointed out that the temporal variation of the TWC is characterized by the propagation of vorticity anomalies originating from northeast of the Taiwan Strait, which further demonstrated that the fluctuations of TWC were associated with its upstream currents such as the TSC.

To explore the spatial distribution of synoptic fluctuations of the wintertime TWC on the ECS shelf, current data with high resolution in both space and time are required. Previous studies on the wintertime TWC were based on cruise surveys (Su and Pan, 1987; Chen et al., 1994; Chen and Wang, 1999), anchored mooring observations (Zhu et al., 2004; Zeng et al., 2012; Huang et al., 2016) and numerical simulations (Guo et al., 2003, 2006; Yang et al., 2011, 2012; Xuan et al., 2012a, 2016). The observation data are limited in terms of temporal and spatial coverage; hence, they cannot fully reveal the synoptic fluctuations of the TWC and their regional differences. Numerical simulations provide a promising approach for studying the overall structure and driving mechanisms of synoptic fluctuations of the TWC in more detail.

In this study, the Finite Volume Coastal Ocean Model (FVCOM; Chen et al., 2003) is used to investigate wintertime TWC synoptic fluctuations and their mechanisms. The rest of this paper is organized as follows. In Sect. 2, we provide a description of methods and validation. The mean distribu- tion, synoptic fluctuations and dynamic diagnostics of the wintertime TWC are given in Sect. 3. The impact of synoptic fluctuation on water exchange is further discussed in Sect. 4, followed by conclusions in Sect. 5 .

\section{Methods and validation}

\subsection{Model configuration}

To investigate the currents (TWC, Kuroshio Current, ZMCC, etc.) and their synoptic fluctuations on the ECS shelf, a threedimensional (3-D) unstructured-grid (Fig. 2, left panel) FVCOM is developed for the entire Bohai, Yellow and East China Seas (part of the Japan/East Sea, and part of the Pacific Ocean). A regional refinement of the resolution (approximately $3 \mathrm{~km}$ ) is specified around the ECS shelf break at the $200 \mathrm{~m}$ isobaths, where a strong excursion of the Kuroshio Current also occurs. The General Bathymetric Chart of the Oceans (GEBCO) provides high-resolution (approximately $1 \mathrm{~km}$ ) bathymetric data (Smith and Sandwell, 1997). In all, 20 vertical layers with 76954 triangle cells were specified in the water column in a sigma-stretched coordinate system.

The driving forces of the numerical simulation include tides, river discharge, surface heat fluxes, wind and openboundary conditions. Harmonic constants of 11 major tidal constituents $\left(\mathrm{M}_{2}, \mathrm{~S}_{2}, \mathrm{~N}_{2}, \mathrm{~K}_{2}, \mathrm{~K}_{1}, \mathrm{O}_{1}, \mathrm{P}_{1}, \mathrm{Q}_{1}, \mathrm{M}_{4}, \mathrm{MS}_{4}\right.$ and $\mathrm{MN}_{4}$ ) were used; these are based on the Oregon State University global inverse tidal model TPXO.7.0 (Egbert et al., 1994; Egbert and Erofeeva, 2002). The daily mean river discharge of the Changjiang and Huanghe was taken from publicly available observation data at the Datong hydrometric station (http://yu-zhu.vicp.net/). Other rivers were not included because of their small discharges; e.g., the Qiantang River, with the largest runoff from the Zhejiang coast, has a climatological mean discharge in winter of about $230 \mathrm{~m}^{3} \mathrm{~s}^{-1}$, which is nearly negligible compared to the Changjiang winter discharge of about $11500 \mathrm{~m}^{3} \mathrm{~s}^{-1}$. The daily mean heat fluxes were from the objectively analyzed air-sea fluxes ( $\mathrm{Yu}$ and Weller, 2007), and the 3-hourly wind stress and $10 \mathrm{~m}$ wind speed data were from the ERA-Interim re-analysis (Dee et al., 2011). The open-boundary conditions, including daily temperature, salinity and fluxes at the Taiwan Strait, the western Pacific Ocean and the Japan/East Sea, were obtained from the Hybrid Coordinate Ocean Model (Bleck, 2002) and interpolated onto the FVCOM model grid points. The temporal resolution of all the driving force fields is better than or equal to 1 day, which is essential to resolve synoptic fluctuations.

The hindcast outputs of sea surface height, temperature, salinity and velocities for the 5 years of simulation from 2009 to 2013 are used, following three spin-up years (2006-2008) initiated with the temperature and salinity taken from the Hybrid Coordinate Ocean Model and velocity set to zero. The initial conditions are ramped-up over a period of 30 days and 

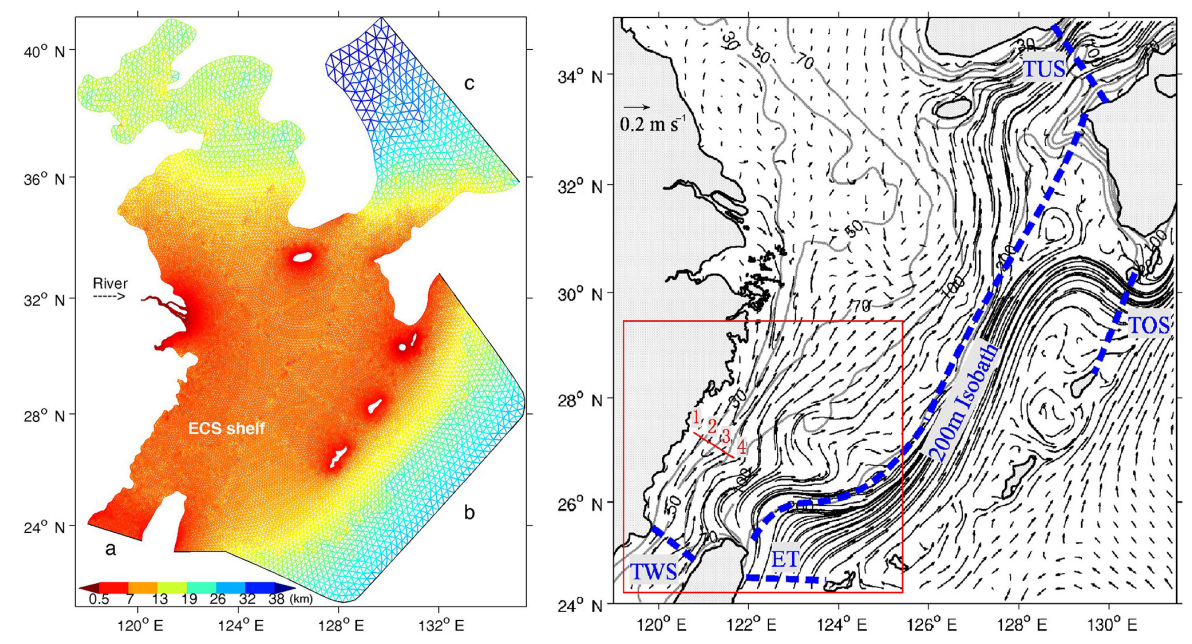

Figure 2. The FVCOM model grid (left panel) and the surface mean flow in the ECS in winter (right panel). The colors in the left panel show the grid length $(\mathrm{km})$. The letters a-c indicate the three open boundaries at the Taiwan Strait, the northwest Pacific Ocean and the Japan/East Sea, respectively. The blue dashed lines (right panel) show some important straits around shelf boundary, including the Taiwan Strait (TWS), the East Taiwan Channel (ET), the Tsushima Strait (TUS), the Tokara Strait (TOS) and shelf break at the $200 \mathrm{~m}$ isobath. The red rectangle shows the study area of the wintertime TWC. The four red numbers off the Zhe-Min coast show the four mooring sites observed from 5 January to 28 February 2009.

at the lateral boundaries a sponge layer was used with the same method as Chen et al. (2008). The model time step was 15 seconds for the 2-D barotropic mode and 90 seconds for the 3-D baroclinic mode. All of the output fields were processed with a tidal filter (Godin, 1972) to remove tidal oscillations (considering that the major timescale of synoptic fluctuations in this study area is $3-15$ days).

Since the currents in 2009 could partly be validated by means of available observational data (see Sect. 2.2), the currents from 1 January to 28 February 2009 were selected for analysis of the wintertime TWC.

\subsection{Validation of the mean currents and synoptic fluctuations}

The mean currents, e.g., the Kuroshio Current, the TWC, and the ZMCC, were calculated by averaging the outputs of January and February 2009. We validated the mean currents in terms of circulation structure, boundary fluxes, and coastal currents.

The FVCOM has reproduced almost all of the known circulation structure in the ECS in winter. The surface mean currents (Fig. 2) show three major currents: the Kuroshio Current, the TWC and the ZMCC. The Kuroshio Current, with a speed of about $1 \mathrm{~m} \mathrm{~s}^{-1}$, enters the ECS just northeast of Taiwan and flows along the shelf break up to the northern area and ultimately leaves the ECS through the Tokara Strait. Both the route and strength of the Kuroshio are comparable with those reported in the literature (Guan, 1978; Qiu and Imasato, 1990). The TWC has two northeastward branches, one inshore (between the 30 and $100 \mathrm{~m}$ isobaths) and another offshore (between the 100 and $200 \mathrm{~m}$ isobaths), which is consistent with Su and Pan (1987). The southwestward-directed ZMCC in the nearshore area from the Changjiang Estuary to the Taiwan Strait agrees well with that reported in previous studies (Guan and Mao, 1982; Zeng et al., 2012).

The simulated volume transports across the Taiwan Strait, the East Taiwan Channel, the Tsushima Strait, the Tokara Strait and the shelf break of the $200 \mathrm{~m}$ isobath were validated using results from the literature (Table 1). The simulated transports were accurate enough to reproduce volume transport $(1.22 \mathrm{~Sv})$ through the Taiwan Strait, which is closer to the observation value $(1.20 \mathrm{~Sv})$ from Isobe (2008) than former model results. The volume transports across the Taiwan Strait and the Tokara Strait, as well as the cross-shore exchange, affected the path and magnitude of the TWC. The annual-mean transport across the $200 \mathrm{~m}$ isobath toward the shelf is $1.66 \mathrm{~Sv}$, which is balanced by the inflow from the Taiwan Strait (1.22 Sv) and the outflow through the Tsushima Strait $(2.85 \mathrm{~Sv})$.

Figure 3 shows a comparison between simulation and observation results for the alongshore currents and the crossshore currents on the ECS shelf. The observational data were obtained from four mooring surveys (Fig. 2, red stations) off the Zhe-Min coast (Zeng et al., 2012). The observed and simulated currents were both averaged for the observational period, which was from 1 January to 28 February 2009. Using the same method as in Huang et al. (2016), we defined the positive alongshore current direction as from the southwest $\left(218^{\circ}\right)$ to the northeast $\left(38^{\circ}\right)$, which is the mean tangential direction of the isobaths on the southwestern shelf of the ECS. The positive cross-shore direction is from the north- 

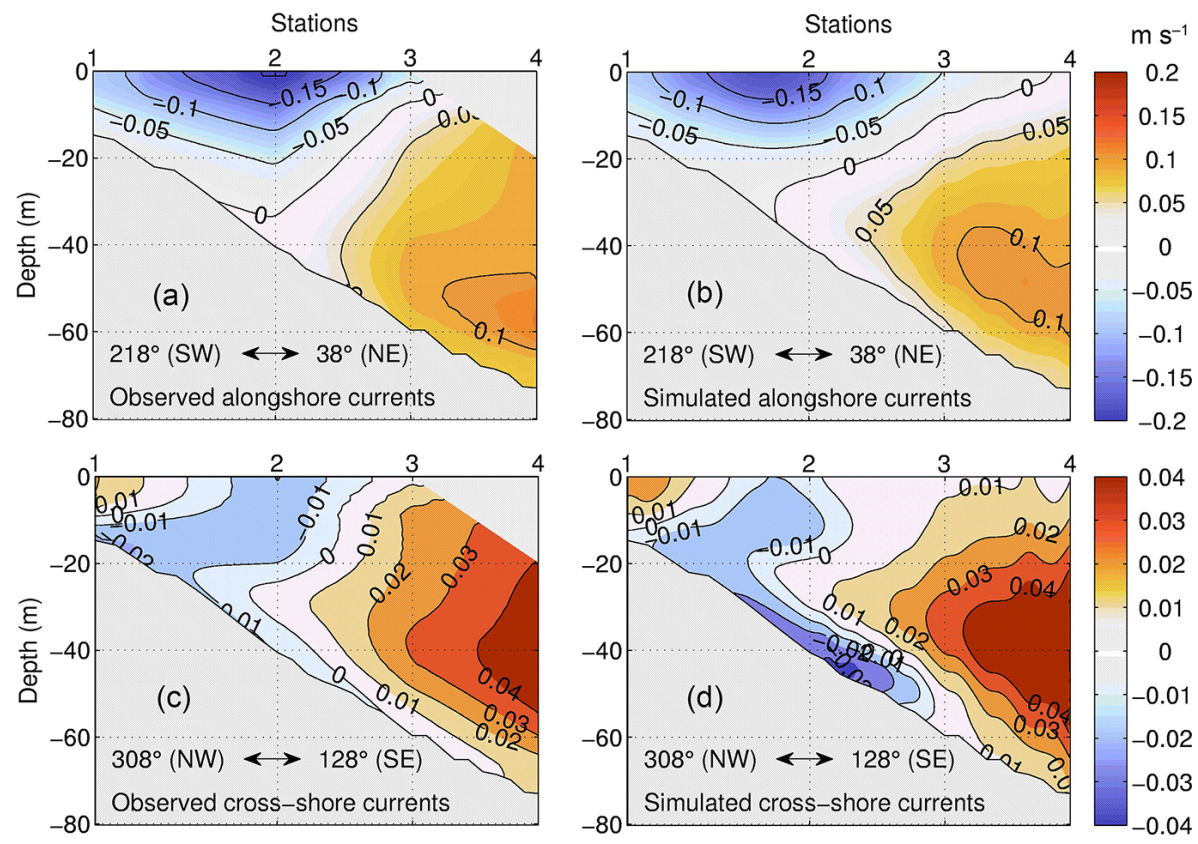

Figure 3. Validations of the wintertime TWC (warm color) along the section off the Zhe-Min coast (the short line with four red numbers in Fig. 2): (a) observed alongshore currents, (b) simulated alongshore currents, (c) observed cross-shore currents and (d) simulated cross-shore currents. Note, an enlarged color scale is used for the cross-shore component to have a clear view of its weak structure.

west $\left(308^{\circ}\right)$ to the southeast $\left(128^{\circ}\right)$, normal to the isobaths. The alongshore components (Fig. $3 \mathrm{a}$ and $\mathrm{b}$ ) show that the ZMCC flows southwestward parallel to the coast in winter, with a maximum speed of $0.15 \mathrm{~m} \mathrm{~s}^{-1}$ along the $30 \mathrm{~m}$ isobath. The TWC flows northeastward with a speed of $0.05 \mathrm{~m} \mathrm{~s}^{-1}$, and the core is located in the lower layer at about $50 \mathrm{~m}$ at station 4. The cross-shore component (Fig. $3 \mathrm{c}$ and d) is much weaker than the alongshore components, and it shows a complex spatial pattern. It flows offshore in the upper layer and onshore in the lower layer at station 1. Moreover, it mainly flows onshore at station 2, and it flows offshore in the entire water column at stations 3 and 4 . Altogether, the simulated pattern and magnitude both of the alongshore and cross-shore components are in good agreement with the observations. However, there are some differences between the observed and simulated results; for example, the simulated ZMCC occupies a broader space than that in the observations. This may have been caused by the relatively low number of observational stations.

Synoptic fluctuations of the TWC inshore branch during January and February 2009 were also validated against the mooring results (Fig. 4). Since the TWC shows a strong signature at station 4 , the time series of the alongshore currents and cross-shore currents in the whole water column of station 4 were used for the validation. To eliminate the influence of local effects, the simulated currents were averaged in a $10 \times 10 \mathrm{~km}^{2}$ area around station 4 . Both the observed and simulated results show that the TWC fluctuates with a period of 3-15 days. The simulated TWC (Fig. 4a, warm color) ap- peared stronger $\left(>0.1 \mathrm{~m} \mathrm{~s}^{-1}\right)$ on 7, 12, 18, 21, 26 and $29 \mathrm{Jan}$ uary, and 10, 14, 19, 22 and 25 February, which agrees well with data from the observations (Fig. 4b). The time series of the simulated cross-shore component (Fig. 4c) are virtually in phase with the observations (Fig. 4d). The magnitude of the cross-shore fluctuations is comparable to the alongshore fluctuations. This is different to the anisotropic characteristic of the mean currents (Fig. 3), for which the alongshore component is nearly 1 order of magnitude larger than the crossshore component.

\subsection{EOF analysis of synoptic fluctuations}

The empirical orthogonal function (EOF) method (Emery and Thomson, 2001), as a statistical method, has been used to understand synoptic fluctuations of the wintertime TWC. The simulated currents from 1 January to 28 February 2009 were selected and their anomalies were calculated. Then, using the Matlab EOF function, the current vectors were separated into several orthogonal modes to show the spatial and temporal variations. Because the first two leading modes explain $91 \%$ of the total variance, only these two modes were used for the analysis.

The spatial distributions of the two leading EOF modes were used to analyze the regional difference of the synoptic fluctuations. To investigate the driving force of the two EOF modes, the temporal variation was compared to the potential influence factors, such as wind, upstream currents and net surface heat flux. 


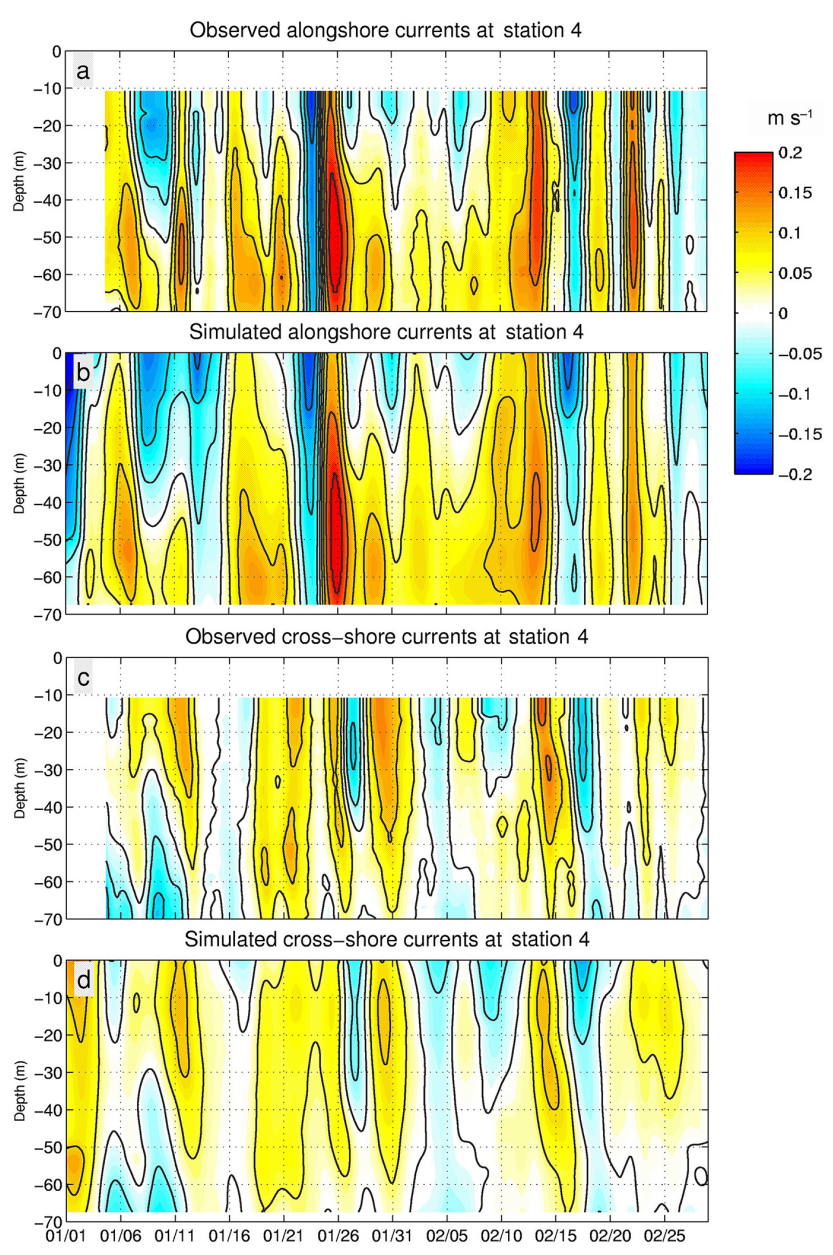

Figure 4. Validations of the wintertime TWC fluctuations: (a) observed alongshore currents, (b) simulated alongshore currents, (c) observed cross-shore currents and (d) simulated cross-shore currents. The observation data come from station 4 in Fig. 1 and the simulated data have the same position and period as the observation data.

\subsection{Momentum analysis}

The driving mechanisms of the synoptic fluctuations were further analyzed using the momentum equation. First, the momentum balance as implemented in FVCOM (Chen et al., 2003) is shown in Eq. (1). The three terms on the left-hand side represent local acceleration, Coriolis acceleration and advection, and the three terms on the right-hand side represent pressure gradient, friction and diffusion.

$$
\frac{\partial \boldsymbol{V}}{\partial t}-2 \boldsymbol{\Omega} \times \boldsymbol{V}+(V \cdot \nabla \boldsymbol{V})=-\frac{1}{\rho_{0}} \nabla P+\frac{\partial}{\partial z}\left(K_{m} \frac{\partial \boldsymbol{V}}{\partial z}\right)+\boldsymbol{F},
$$

where $\boldsymbol{V}$ is velocity, $\boldsymbol{\Omega}$ is the Earth's rotation angular velocity, $\rho_{0}$ is the average density, $P$ is pressure, $K_{m}$ is the vertical eddy viscosity coefficient and $\boldsymbol{F}$ is horizontal diffusion.

Second, according to the hydrostatic approximation used in FVCOM (as shown in Eq. 2), the pressure gradient is given
Table 1. Annual-mean volume transports $\left(\mathrm{Sv}=10^{6} \mathrm{~m}^{3} \mathrm{~s}^{-1}\right)$ through various sections. The sections are shown in Fig. 2 using blue dashed lines.

\begin{tabular}{|c|c|c|}
\hline Section & $\begin{array}{r}\text { Present } \\
\text { model }\end{array}$ & Previous estimates \\
\hline Taiwan Strait & 1.22 & $\begin{array}{l}1.2 \text { (Isobe, 2008) } \\
1.8 \text { (Wang et al., 2003) } \\
1.09 \text { (Wu and Hsin, 2005) } \\
1.03 \text { (Yang et al., 2011) } \\
1.72 \text { (Guo et al., 2006) } \\
0.5 \text { (Hung et al., 2003) } \\
1.10 \text { (X. Liu et al., 2014b) }\end{array}$ \\
\hline Tsushima Strait & 2.85 & $\begin{array}{l}2.65 \text { (Isobe, 2008) } \\
3.03 \text { (Guo et al., 2006) } \\
2.70 \text { (Yang et al., 2011) } \\
2.52 \text { (X. Liu et al., 2014b) }\end{array}$ \\
\hline $200 \mathrm{~m}$ isobath & 1.66 & $\begin{array}{l}1.46 \text { (Guo et al., 2006) } \\
0.87 \text { (C. Liu et al., 2014a) } \\
3.0 \text { (Teague et al., 2003) } \\
2.74 \text { (Lee and Matsuno, 2007) }\end{array}$ \\
\hline East Taiwan Channel & 22.71 & $\begin{array}{l}21.50 \text { (Johns et al., 2001) } \\
23.00 \text { (Teague et al., 2003) } \\
23.83 \text { (Guo et al., 2006) } \\
28.4 \text { (Hsin et al., 2013) } \\
\text { 21.37 (Yang et al., 2011) } \\
\text { 20.74 (X. Liu et al., 2014b) }\end{array}$ \\
\hline Tokara Strait & 23.20 & $\begin{array}{l}23.4 \text { (Feng et al., 2000) } \\
20.00 \text { (Teague et al., 2003) } \\
20.66 \text { (Yang et al., 2011) } \\
24.42 \text { (X. Liu et al., 2014b) }\end{array}$ \\
\hline
\end{tabular}

as the product of density times the gravitational acceleration. This results in Eq. (3), which indicates that pressure gradient can be decomposed into the effects of the barotropic and baroclinic components, as shown in Eq. (4).

$$
\begin{aligned}
& \frac{\partial P}{\partial z}=\rho g \\
& P_{z}=\int_{z}^{\eta} \rho g \mathrm{~d} z=\int_{z}^{\eta}\left(\rho_{0}+\rho^{\prime}\right) g \mathrm{~d} z=\rho_{0} g(z+\eta)+\int_{z}^{\eta} \rho^{\prime} g \mathrm{~d} z \\
& \nabla \boldsymbol{P}=\rho_{0} g \nabla \eta+\nabla\left(\int_{z}^{\eta} \rho^{\prime} g \mathrm{~d} z\right)
\end{aligned}
$$

where $\rho$ is density, $\rho^{\prime}$ is density anomaly, $g$ is the gravitational acceleration and $\eta$ is sea surface height.

Finally, the momentum equation is vertically integrated to estimate momentum balance for the water column. Since the horizontal diffusion is a comparatively small term, it is neglected for simplicity. 

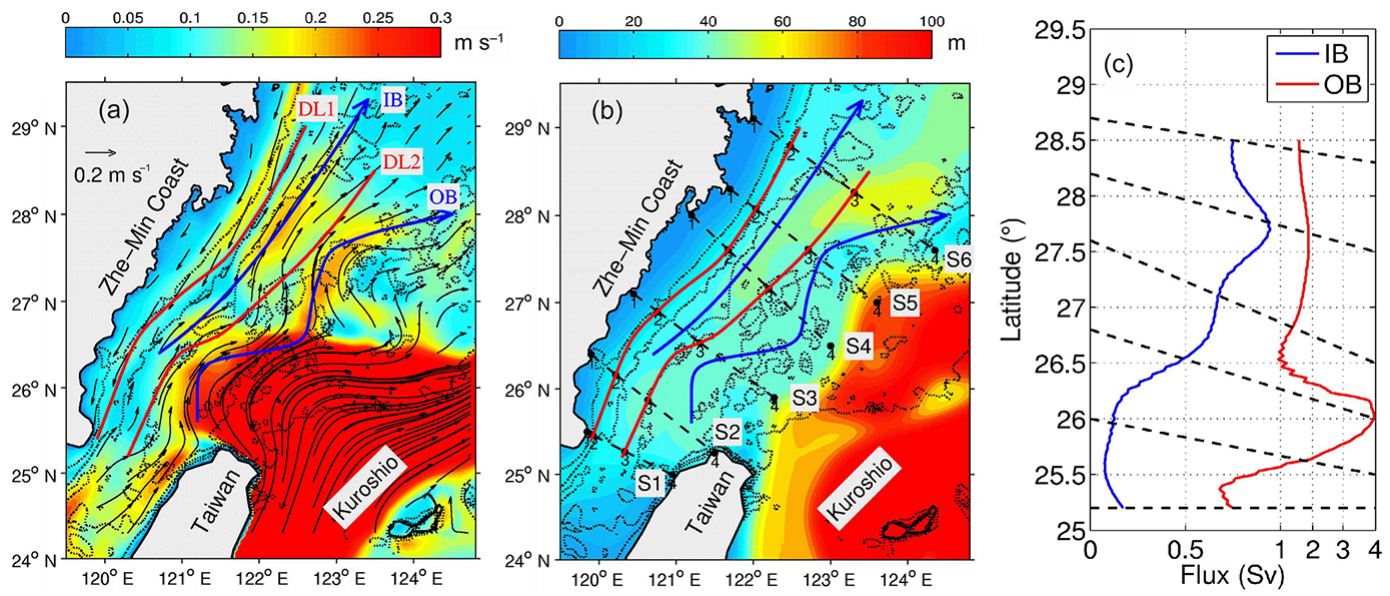

Figure 5. (a) Distribution of flow axes in the ECS in winter. The black arrows show the maximum velocity ( $\mathrm{m} \mathrm{s}^{-1}$ ) in the vertical profile (VMV) and the color shows the speed of the VMV. The two blue arrows labeled IB and OB represent the flow axes of the inshore branch and offshore branch. The red line DL1 represents the dividing line between the coastal current and inshore branch, and the red line DL2 separates the two TWC branches. (b) Depth (m) of flow axes in the ECS are shown by color. Sections S1-S6 were selected to study the wintertime TWC. (c) Flux of inshore branch (blue) and offshore branch (red) at different latitudes. Dashed lines show the positions of Sections S1-S6. Note, the scale is not linear.

$$
\begin{array}{r}
\underbrace{\int_{-H}^{0} \frac{\partial \boldsymbol{V}}{\partial t}}_{\text {Acceleration }}+\underbrace{\int_{\text {Advection }}^{0}-2 \boldsymbol{\Omega} \times \boldsymbol{V}+\int_{-H}^{0}(V \cdot \nabla \boldsymbol{V})}_{\text {Coriolis }} \\
=\underbrace{\underbrace{-g H \nabla \eta}_{\text {Total Pressure }}-\underbrace{\int_{-H}^{0} \nabla\left(\int_{z}^{\eta} \rho^{\prime} g \mathrm{~d} z\right)}_{\text {Baroclinic }}}_{\text {Barotropic }} \\
+\underbrace{\rho_{\mathrm{a}} C_{\mathrm{D}}|\boldsymbol{U}| \boldsymbol{U}-k_{\mathrm{b}}\left|\boldsymbol{V}_{\mathrm{b}}\right| \boldsymbol{V}_{\mathrm{b}}}_{\tau_{\mathrm{a}}},
\end{array}
$$

where $\tau_{\mathrm{a}}$ is wind stress and $\tau_{\mathrm{b}}$ is bottom stress, $\rho_{\mathrm{a}}$ is the density of air, $\boldsymbol{U}$ is the wind speed at $10 \mathrm{~m}$ above sea surface, $C_{\mathrm{D}}$ is a drag coefficient at the sea surface (which varies with wind speed $\boldsymbol{U}), k_{\mathrm{b}}$ is a bottom friction coefficient $\left(k_{\mathrm{b}}=0.005\right)$ and $\boldsymbol{V}_{\mathrm{b}}$ is the simulated velocity at the bottom.

\section{Results}

\subsection{Mean distribution of TWC in winter}

Since the observational results (Su and Pan, 1987; Zeng et al., 2012) show that both branches of the wintertime TWC are flowing in the subsurface, we use the vertical maximum velocity (VMV) and its corresponding depth as two indices to quantify the strength of the subsurface currents (Fig. 5).

As stated above, the distribution of the VMV shows two branches of the TWC (Fig. 5a). The inshore branch (Fig. 5a, blue arrow of IB), which was located between the 30 and $100 \mathrm{~m}$ isobaths, followed a straight route from the northwest of Taiwan to the northern ECS shelf. The offshore branch (Fig. 5a, blue arrow of OB) existed near the $100 \mathrm{~m}$ isobath and had two meanders. The two meanders turn to the crossshore direction along latitudes 26.5 and $28^{\circ} \mathrm{N}$. These two branches are further illustrated in the distributions of current speed along the six TWC cross sections (S1-S6), which were located at critical points in the two meanders (Fig. 6). From the VMV structure, it can be inferred that the intrusions of the TSC and the Kuroshio Current both affected the origin of the offshore branch (Fig. 6, S1-S3).

We further examined the subsurface current core using the depth of the VMV (Fig. 5b). We found that the VMV of the TWC was located $40-60 \mathrm{~m}$ below the surface at the inshore branch and $20-40 \mathrm{~m}$ below the surface at the offshore branch. Figure 6 shows the VMV positions in the subsurface layer; furthermore, it illustrates that the depth of the subsurface VMV in the inshore branch was deeper than that in the offshore branch. The difference can be explained by the combined effects of baroclinicity and wind friction. Assuming a relatively spatially homogeneous heat loss, different cooling occurs, due to the smaller heat capacity of the shallow coastal water compared to the deeper offshore waters, hence generating a northwestward horizontal density gradient leading to a northeastward thermal current (vertical current shear) according to the thermal wind relationship, resulting in an upward-increasing northeastward flow. The northeasterly wind in winter weakens the northeastward TWC, particularly in the upper layer, which leads to the formation of the subsurface VMV. Therefore, the fact that the depth of the subsurface current core in the inshore branch 


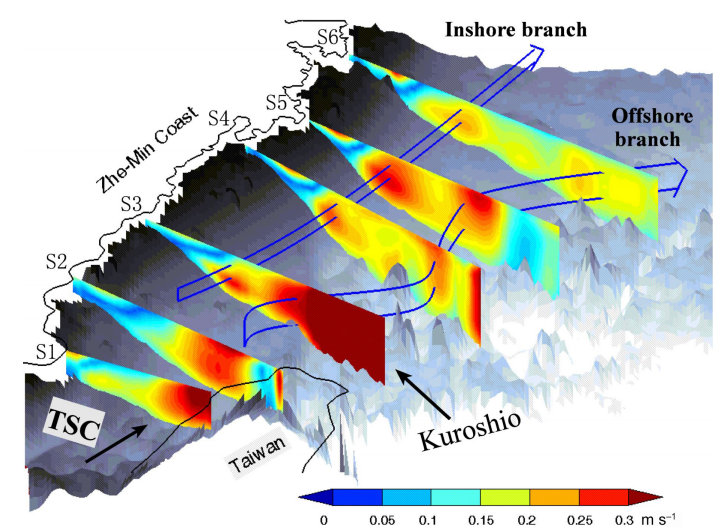

Figure 6. Distributions of current speed along the six sections S1$\mathrm{S} 6$ in winter. The blue arrow on the left indicates the inshore branch according to the velocity cores from section S3 to S6. The blue arrow on the right indicates the offshore branch according to the velocity cores from section S2 to S6. TSC is the Taiwan Strait Warm Current.

is greater than that in the offshore branch indicates weaker baroclinicity or stronger wind friction on the inshore branch than on the offshore branch.

The magnitude of the wintertime TWC was obtained by flux analysis. Two dividing lines (Fig. 5a, red lines) were defined as the boundaries for the ZMCC: the TWC inshore branch, and the TWC offshore branch, which had the weakest flows. The flux of each branch (Fig. 5c) was calculated using the horizontal integration between the boundaries and the vertical integration in the water column. The inshore branch intensifies along its way and becomes significant north of $26.5^{\circ} \mathrm{N}$, showing particularly strong flow velocities between 27.5 and $28.0^{\circ} \mathrm{N}$. In this area, the subsurface current was much stronger from S4 to S5 than in the other areas (Fig. 6). The flux in the entire offshore branch was large, particularly north of Taiwan.

\subsection{Synoptic fluctuations}

The observations (Fig. 4) have demonstrated that the synoptic fluctuation in the TWC inshore branch (near $121.5^{\circ} \mathrm{E}$, $27.0^{\circ} \mathrm{N}$ ) is significant. We further investigated the regional difference of fluctuations in the two TWC branches in winter 2009 using the following three steps: (i) two regions with significant fluctuations are identified by the current standard deviations of the VMV (Fig. 7) and the corresponding temporal variation of vertical structures at their extremes (Fig. 8); (ii) each of the two significant fluctuations is decomposed into EOF components (Fig. 9); and (iii) the influence factors, such as wind, upstream currents, and net surface heat flux, are investigated by examining their correlations with the first two leading EOF components (Figs. 10 and 11).

The current standard deviations (Fig. 7) show that prominent fluctuations occurred in two regions: north of Taiwan

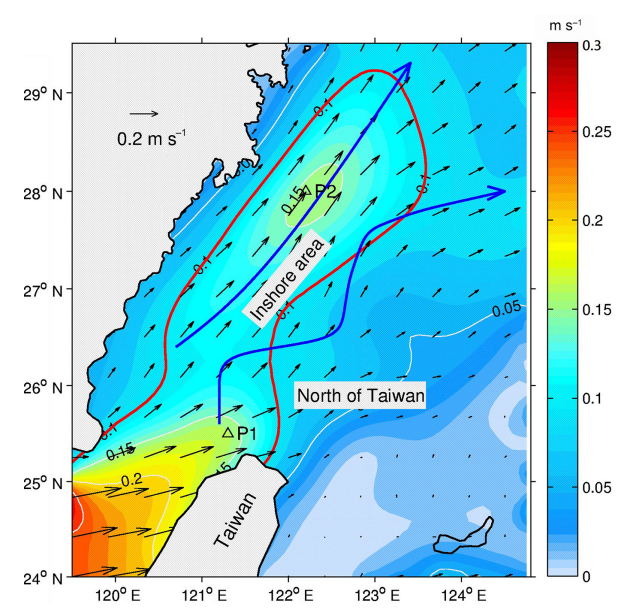

Figure 7. Current standard deviation in the layer of the VMV. The black arrows indicate the major axis of the ellipse, which represent the standard deviation of the current. The color shading shows the respective magnitude. The two blue arrows indicate the two TWC branches. The red curve indicates the area where the current standard deviation is larger than $0.1 \mathrm{~m} \mathrm{~s}^{-1}$ and the branches' representative points (P1 and $\mathrm{P} 2$ ) are selected for later analysis.

and the inshore area. The standard deviations of VMV at the two regions were larger than $0.1 \mathrm{~m} \mathrm{~s}^{-1}$ (comparable to the mean currents). In the area north of Taiwan, the fluctuation was located in the origin area of the TWC offshore branch. The fluctuation in this region was in phase with the fluctuation in the Taiwan Strait, indicating that the TSC played an important role in generating the fluctuation north of Taiwan (to a greater extent than did the Kuroshio intrusion). The TWC fluctuation had a strong cross-shore component, which means the fluctuation transported the water north of Taiwan to both the inshore and offshore branches. In the inshore area, the fluctuations were influencing a wide region between the 30 and $100 \mathrm{~m}$ isobaths, with a magnitude that was sometimes larger than the mean flow (Fig. 5a). These strong fluctuations led to an episodic occurrence of the TWC inshore branch, as observed at the site off the Zhe-Min coast (Fig. 4, red color). When the TWC inshore branch was weakened due to these fluctuations, the ZMCC might even dominate a wide region out to the $100 \mathrm{~m}$ isobath, especially at the surface (Fig. 4, blue color).

The vertical structures of the fluctuations north of Taiwan and in the inshore area at two representative points and their relation with the upper mixed layer depth are further analyzed (Fig. 8). The major component (the alongshore current) of the TWC in each of the two regions (P1 and P2, Fig. 7) is used to show the vertical structure of the fluctuation. The depths of the upper mixed layer were determined by a Richardson number criterion (Mellor and Durbin, 1975; Grachev et al., 2013; Richardson et al., 2013), i.e., where the critical Richardson number equals 0.25 in this paper (as in Xuan et al., 2012b). The mean depth of the upper mixed 

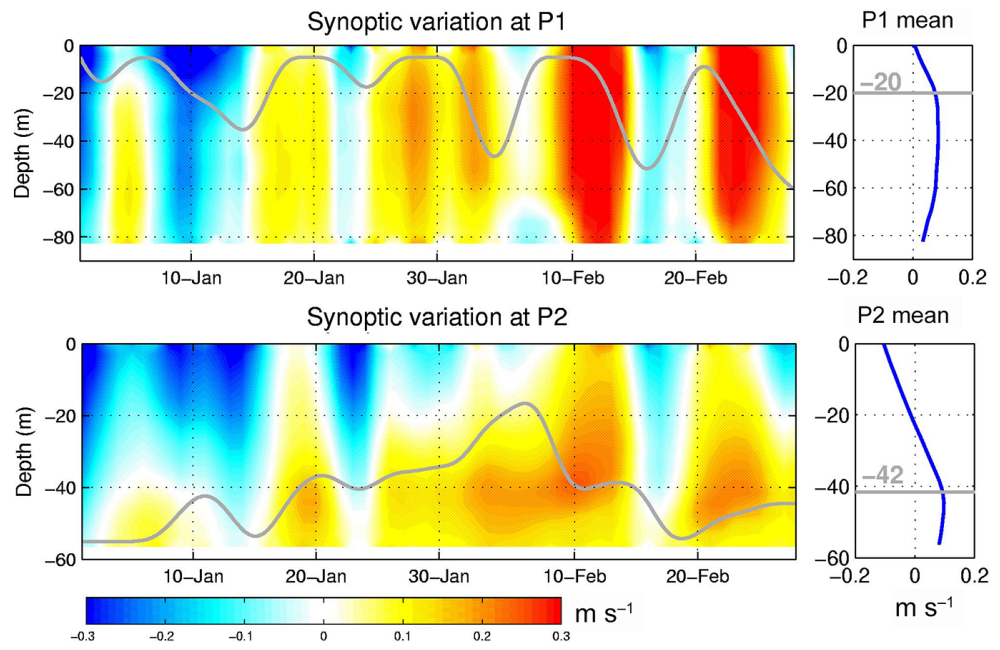

Figure 8. Variation of alongshore currents $\left(\mathrm{m} \mathrm{s}^{-1}\right.$, shown by color scale) for the entire water column north of Taiwan (P1) and in the inshore area (P2) and their relation with upper mixed layer depth. The positive velocity (warm color) indicates the occurrence of the TWC. The gray solid lines show the depth of the upper mixed layer.

layer north of Taiwan $(20 \mathrm{~m})$ was much shallower than the mean depth of the inshore area $(42 \mathrm{~m})$. However, the TWC (Fig. 8, warm color) fluctuated with significant variations of the upper mixed layer depth (Fig. 8, gray lines) in both areas. When the upper mixed layer deepened, the northeastward TWC (Fig. 8, warm color) was weakened or even replaced by the southwestward ZMCC, and vice versa. Wind and surface cooling, which both drive the mixed layer depth, can affect the TWC fluctuation.

The TWC fluctuations were further decomposed into EOF modes. The first two leading EOF modes account for 54 and $37 \%$ of the total variances (Fig. 9), associated with the two prominent fluctuations north of Taiwan and in the inshore area (Fig. 7). Both EOF modes had a maximum fluctuation larger than $0.2 \mathrm{~m} \mathrm{~s}^{-1}$ (comparable to the mean currents). The spatial pattern of the first EOF mode (EOF1; Fig. 9a) shows that the fluctuation continued from the Taiwan Strait to the area north of Taiwan, indicating that the fluctuation north of Taiwan was related to the TSC and not to the Kuroshio Current. The alongshore component also showed a strong fluctuation in the Taiwan Strait, which means that the TSC episodically intruded the shelf. The cross-shore component revealed a fluctuation north of Taiwan that was larger than $0.1 \mathrm{~m} \mathrm{~s}^{-1}$. This cross-shore fluctuation impacted on the trajectory of the Taiwan Strait (TWS) water, synoptically flowing into the TWC inshore branch, offshore branch or Kuroshio Current.

The spatial pattern of the second EOF mode (EOF2; Fig. 9b) shows a synoptic fluctuation in the inshore area. The area with alongshore fluctuation (Fig. 9d) larger than $0.1 \mathrm{~m} \mathrm{~s}^{-1}$ was located between the 30 and $100 \mathrm{~m}$ isobaths, which demonstrates that the TWC could episodically affect this area. In addition, there were cross-shore fluctuations in the inshore area (Fig. 9f), mostly along the latitudes 26.5 and $28^{\circ} \mathrm{N}$. The latitudes of larger cross-shore fluctuations agreed well with the latitudes where the TWC offshore branch of the mean currents (Fig. 5a) turned to the cross-shore direction. This indicated that the cross-shore transports were most significant at the latitudes 26.5 and $28^{\circ} \mathrm{N}$, according to both the mean currents and the synoptic fluctuations.

Figure 10 shows the temporal variation of EOF1 and its relation to the north-south component of wind speed, net surface heat flux, the TSC and the Kuroshio Current. We found a close correlation between EOF1 and TSC $(R=0.86)$, demonstrating that the TSC played the most important role in generating the TWC fluctuation north of Taiwan. The EOF1 and TSC were positively correlated, meaning that a larger TSC intrusion north of Taiwan leads to a cross-shore current from the coastal area to the offshore area and that a weak TSC intrusion causes a cross-shore current from offshore to inshore north of Taiwan.

Figure 11 shows the temporal variation of EOF2 and its relation with the north-south component of wind speed, net surface heat flux, the TSC and the Kuroshio Current. It can be seen that EOF2 and wind are well correlated $(R=0.89)$, indicating the important role of wind in generating the TWC fluctuation in the inshore area. The northeasterly monsoon would greatly enhance the southwestward ZMCC, which would then replace the northeastward TWC in the inshore area.

\subsection{Dynamic diagnostics}

The wintertime (January and February 2009) mean of the water column momentum balance (Fig. 12) is used to show the overall distribution of the fundamental forces over the ECS shelf. The Coriolis force (Fig. 12a) is mainly balanced by the total pressure (Fig. 12b) in both branches, indicating the dominant role of geostrophic balance in the wintertime 

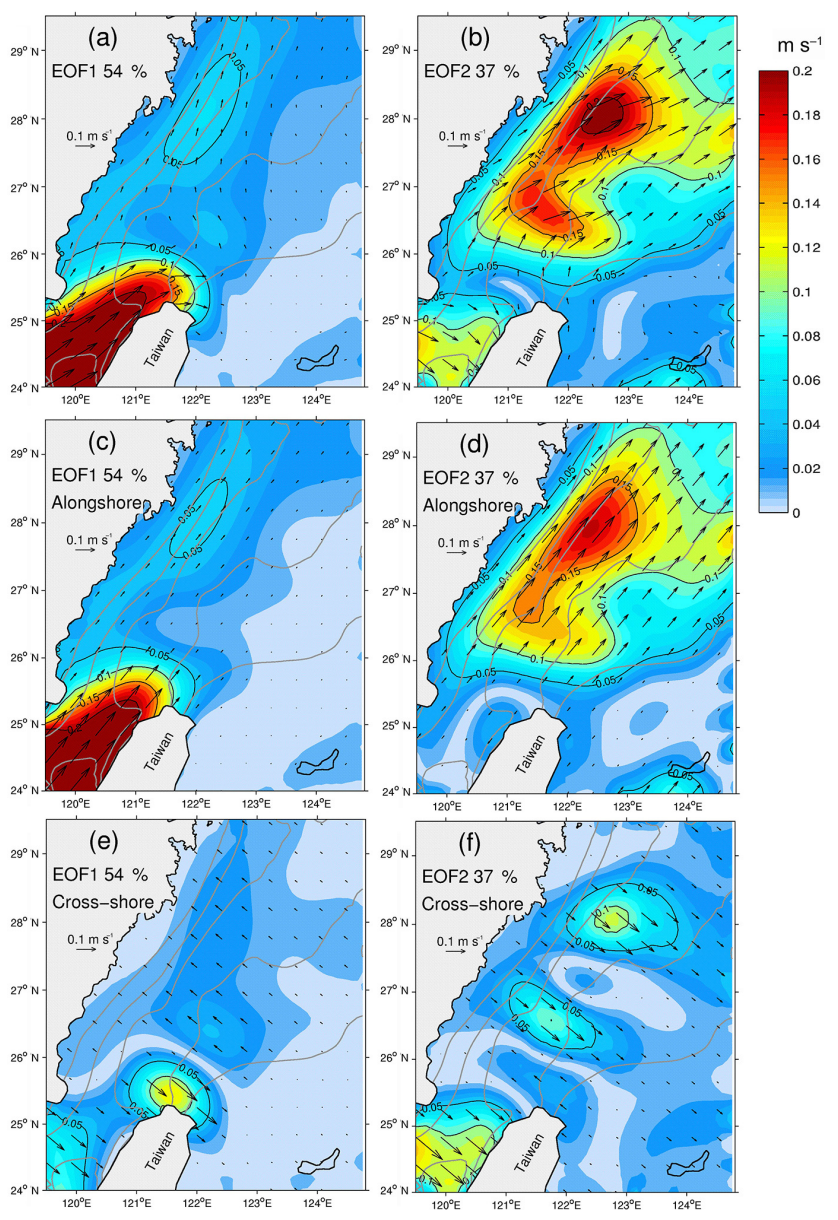

Figure 9. The spatial pattern of the first (EOF1; left panels) and second (EOF2; right panels) leading modes of the VMV in the ECS: (a) EOF1 currents, (b) EOF2 currents, (c) EOF1 alongshore component, (d) EOF2 alongshore component, (e) EOF1 cross-shore component and (f) EOF2 cross-shore component (all shown by black arrows with the color representing the magnitude). The 30, 50, 70, 100 and $200 \mathrm{~m}$ isobaths are indicated with gray lines.

TWC. However, the wind-induced surface friction plays an important role in the TWC, especially in the inshore area and the Taiwan Strait (Fig. 12c). The bottom friction has an impact north of Taiwan and in the shallow Taiwan Strait, in particular when significant Kuroshio intrusion enhances the bottom flow (Fig. 12d). The effects of advection and acceleration are predominantly local indicated by mostly incoherent small-scale distributions (Fig. 12e and f); therefore, they can be ignored when studying the large-scale current of the wintertime TWC.

The variation of the driving forces at two representative points P1 and P2 was used to analyze the dynamics of synoptic fluctuations north of Taiwan and in the inshore area. Regarding the results from the EOF analysis, the three force terms, namely, Coriolis, total pressure and wind (Fig. 13), were selected to investigate the effect of the TSC on the fluc- tuation north of Taiwan (Fig. 9a) and the effect of wind on the fluctuation in the inshore area (Fig. 9b).

In the area north of Taiwan, the cross-shore fluctuations were induced by the TSC intrusion. The variation of alongshore Coriolis force (Fig. 13a, black line) was much greater than the cross-shore Coriolis force (Fig. 13b, black line), which means that the fluctuation north of Taiwan was mainly in the cross-shore direction. The Coriolis force (Fig. 13a, black line) was mainly balanced by the total pressure (Fig. 13a, blue line), which means the currents fluctuations north of Taiwan are dominated by geostrophic balance. As mentioned in Sect. 3.2, the TWC fluctuation north of Taiwan was associated with the TSC rather than with the Kuroshio Current. Therefore, in the shallow coastal area the TSC mainly caused variations in the depth-independent barotropic pressure gradients, which further generated the cross-shore fluctuation. The mechanism can be interpreted as follows. When a larger TSC intrusion occurred, the isobaric slope tilted downward from south to north, generating a cross-shore current from the coastal area to the offshore area. On the contrary, when the TSC intrusion was weak, the Kuroshio intrusion from offshore to inshore dominated north of Taiwan.

Wind friction (Fig. 13c and d) was a fundamental factor in generating the fluctuations in the inshore area. Although the geostrophic balance dominated in the inshore branch for most of the time, the episodically strong winter monsoon had an important role in generating the TWC fluctuations. The northwestward direction Coriolis force (Fig. 13c, black line) shows that the southwestward ZMCC occurred on 12, 22 January and 14 February 2009, and was associated with a northeasterly wind (Fig. 13c, red line). It indicates that strong northeasterly monsoon in winter can reduce or even stop the northeastward TWC in the inshore area, causing the intermittency of the TWC inshore branch.

\section{Discussion}

Simulated results in the winters (December-March) of the years 2010 to 2013 (Fig. 14) show that general structures of the TWC in the other winters were similar to that in winter 2009 (Figs. 5 and 9), which indicates that the results from the winter 2009 can be regarded as representative for the winter situation. The two TWC branches and the two areas of strong fluctuations were present in all winters from 2009 to 2013, although their strength showed a certain interannual variability in accordance with the changing surface forcing and boundary fluxes.

The wintertime TWC, which is manifested by two subsurface branches and significant synoptic fluctuations, has a very different structure when compared with the stationary and surface summertime TWC reported in previous studies (Guan, 1978; Fang et al., 1991; Isobe, 2008). The synoptic events, with timescales of 3-15 days, play a dominant role 

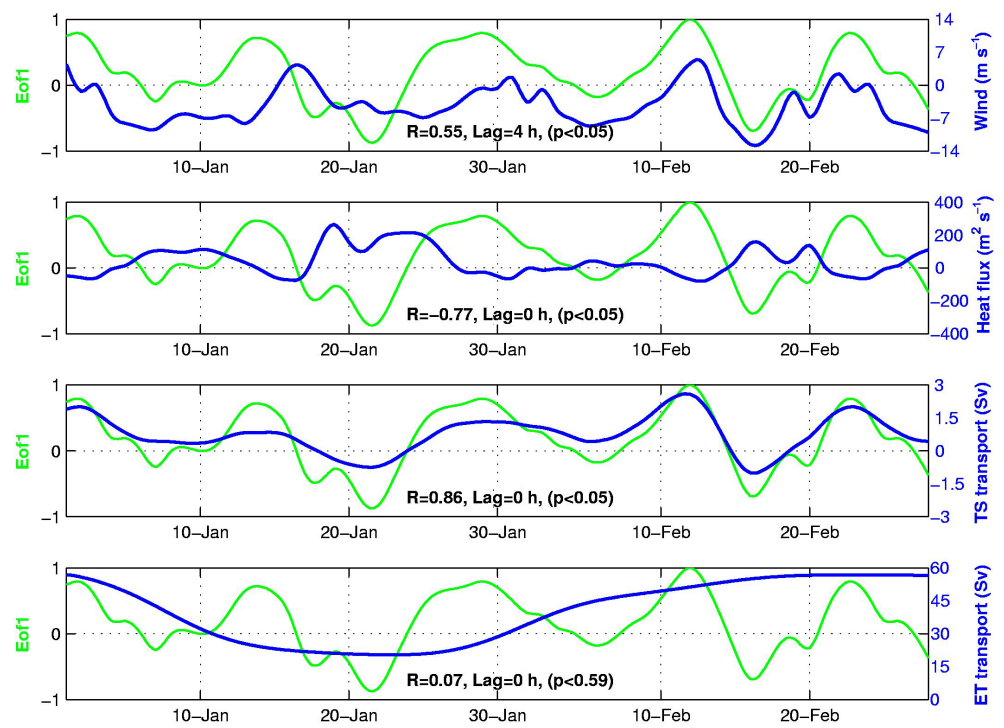

Figure 10. Temporal variation of EOF1, north-south component of wind speed, surface net heat flux, and TSC flux across the TWS section, and Kuroshio flux across the ET section. Their linear correlation coefficients $R$ and time lags are also indicated in each panel. The $p$ value is a declining indicator, which indicates the impact significance of the linear correlation coefficients $R$, whereby $R$ has statistical significance and the confidence level is larger than $95 \%$ when the $p$ value is less than 0.05 .
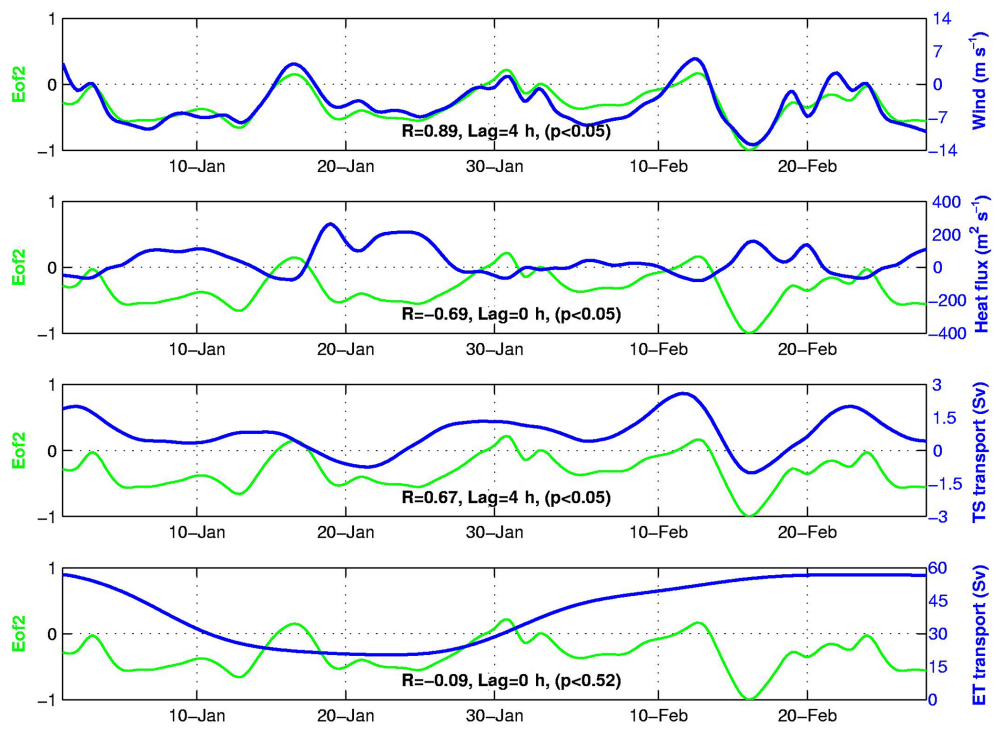

Figure 11. Temporal variation of EOF2, north-south component of wind speed, surface net heat flux, and TSC flux across the TWS section, and Kuroshio flux across the ET section. Their linear correlation coefficients and time lags are also indicated in each panel.

on the horizontal advective transports. According to Ledwell et al. (1998) synoptic variations are much more effective on the horizontal transport than variations on shorter timescales. The synoptic fluctuations modulate the spatial structure of the wintertime TWC, especially when their magnitudes are comparable with that of the mean currents, such as the two prominent fluctuations north of Taiwan and in the inshore area (Fig. 7). Therefore, the two prominent fluctuations will be discussed next in terms of their contributions to the alongshore and cross-shore transports.

\subsection{Cross-shore transport north of Taiwan induced by the TSC}

In the area north of Taiwan, the TSC intrusion generated strong fluctuations of the TWC in the cross-shore direction (Fig. 9a). When a larger TSC intrusion occurred, the isobaric slope tilted downward from south to north, generating 


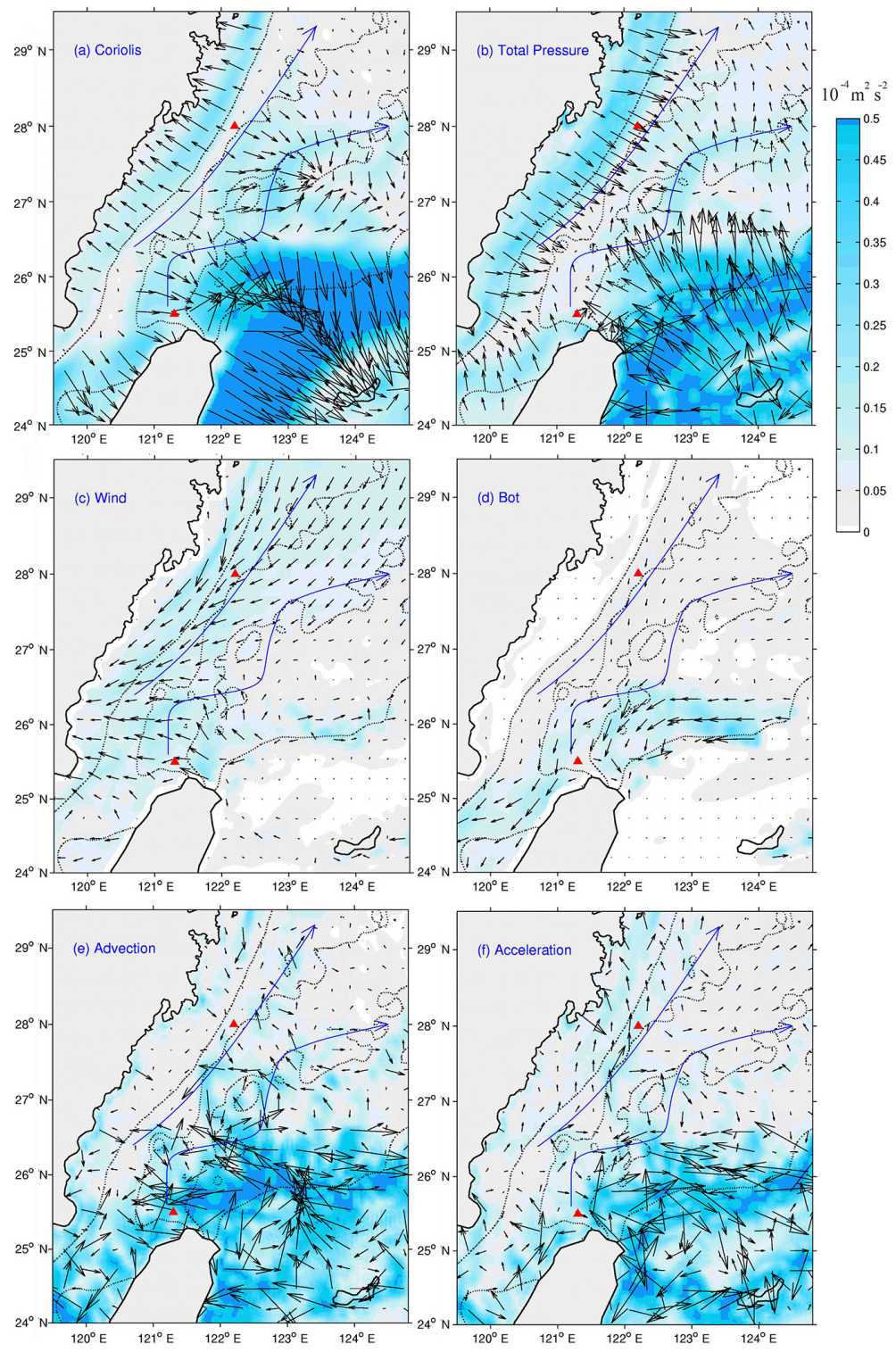

Figure 12. The effects of Coriolis force (a), total pressure (b), surface friction (c), bottom friction (d), advection (e) and local acceleration (f) for water column in winter according to Eq. (5) (shown by black arrows with the color representing the magnitude; units: $10^{-4} \mathrm{~m}^{2} \mathrm{~s}^{-2}$ ). The two blue arrows indicate the two TWC branches. The two triangles indicate the two regions with significant fluctuation north of Taiwan (P1) and in the inshore area (P2).

a cross-shore current from the coastal area to the offshore area. Compared to the reported summer route that transports Taiwan Strait water to the inshore area between the 30 and $100 \mathrm{~m}$ isobaths (Guan, 1978; Fang et al., 1991; Isobe, 2008; Yang et al., 2011, 2012), our results showed that most Taiwan Strait water was transported to the TWC offshore branch and to the Kuroshio area as a result of the cross-shore fluctuations induced by the synoptic TSC intrusion.

A numerical tracer simulation was used to analyze the role of the cross-shore fluctuation in the transport of the TSC water and the Kuroshio water north of Taiwan. In order to demonstrate the characteristics of the flow patterns more clearly, artificial tracers are released in the model domain and transported by the velocity field provided by the FV$\mathrm{COM}$ simulation. The tracer running was part of the FVCOM simulation; therefore, all the abovementioned dynamics were involved, e.g., tide, wind and boundary forces. The release location and start date of the particles were configured as follows. Two sections, one in the Taiwan Strait (Fig. 15a, black dots) and another in the East Taiwan Channel (Fig. 15b, black dots), were selected as the source locations for the water masses of the TSC and the Kuroshio, respectively. The particles were released on 1 January 2009 and tracked until 31 March 2009 (a total of 90 days). 

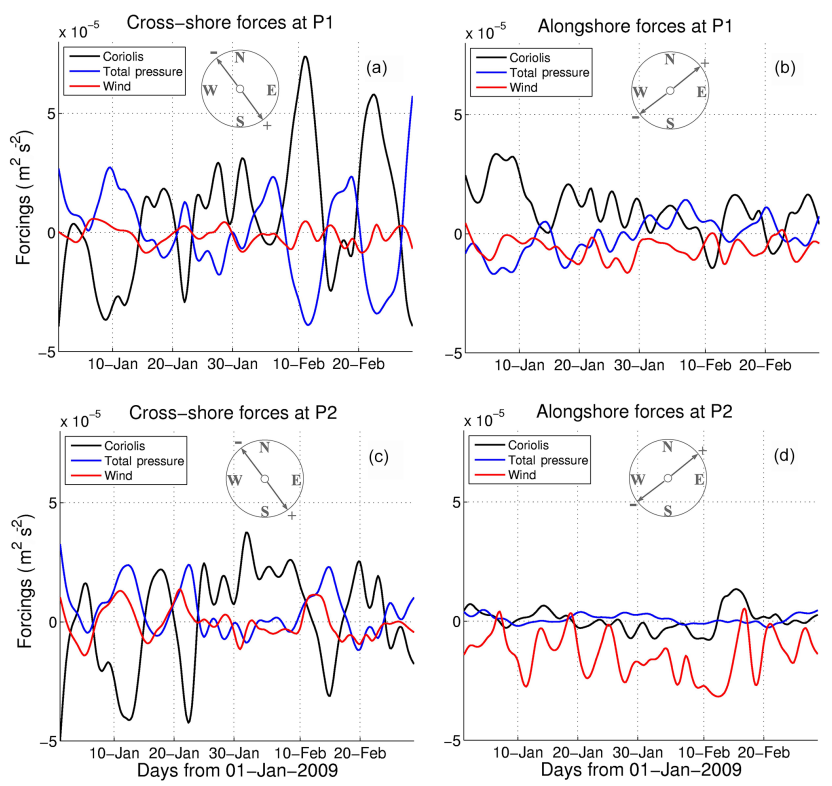

Figure 13. Variations in Coriolis force, total pressure, and wind in the cross-shore direction at P1 (a), the alongshore direction at P1 (b), the cross-shore direction at P2 (c) and the alongshore direction at P2 (d) according to Eq. (5). The gray pointers indicate the alongshore and cross-shore directions of dynamical effects in the Earth coordinate system.

Figure 15a shows the traces originating from the TSC area. Unlike the traditional route, where the TSC water flows from the Taiwan Strait to the inshore area between the 30 and $100 \mathrm{~m}$ isobaths, most particles (Fig. 15a, gray lines) were concentrated in the offshore branch under the effect of crossshore fluctuation. Two particles were selected to show the inshore route (Fig. 15a, red line) and offshore route (Fig. 15a, blue line), with both passing the area north of Taiwan. When the two particles arrived at the area north of Taiwan, the behavior of the tracers, according to specific velocity conditions (Fig. 15c), was very different; a northwestward transport occurred on 25 January for the inshore particles (Fig. 15c) and a northeastward transport occurred on 12 February for the offshore particles (Fig. 15c). The velocity conditions in the area north of Taiwan corresponded to the variation of the Taiwan Strait flux (Fig. 10), which shows that the Taiwan Strait flux on 12 February was much greater than on 25 January. Therefore, it can be concluded that the TSC intrusion induced an offshore transport north of Taiwan.

Figure $15 \mathrm{~b}$ shows the traces originating from the Kuroshio area. In the same way as the TSC water, the Kuroshio water was also transported to the northern shelf via both the inshore branch and the offshore branch. The separation of the two branches north of Taiwan was caused by cross-shore fluctuations of the currents. When the two particles arrived at the area north of Taiwan, a northwestward transport occurred on Feb. 2 for the inshore particles (Fig. 15c) and a northeastward transport occurred on Feb. 12 for the offshore particles
(Fig. 15c). This means that the offshore transport induced by the TSC also had an effect on the distribution of Kuroshio water north of Taiwan. Liu et al. (2016) showed that the winter TSC originated from a small branch of Kuroshio intrusion into the Luzon Strait. Our results complement this picture, since they show that most TSC particles flow into the TWC offshore branch under the influence of cross-shore fluctuation.

Our results may underestimate the impact of Kuroshio intrusion on the fluctuation of the TWC northeast of Taiwan, especially at the seasonal and interannual timescales. Wei et al. (2013) demonstrated that the annual and interannual variations of the Kuroshio volume transport are large. In addition, Zhou et al. (2015) pointed out that the annual and interannual variations of the Kuroshio intrusion northeast of Taiwan are prominent. X. Liu et al. (2014b) presented supportive evidence that the Kuroshio intrusion, from east of Taiwan to the onshore area north of Taiwan, is closely related to the Kuroshio volume transport. This relation between the Kuroshio intrusion and the Kuroshio volume transport had been interpreted by Su and Pan (1987) as the $\beta$ effect because of the sudden change in topography northeast of Taiwan. Our results show that the intraseasonal variation of the Kuroshio intrusion and the Kuroshio volume transport was negligible compared with the TSC variation at the same timescale, indicating that the synoptic fluctuation of TWC north of Taiwan is mainly induced by the TSC. However, because FVCOM uses sigma coordinates in the vertical that are prone to errors in regions of steep topography, our results may underestimate the fluctuations at the shelf break, in particular to the northeast of Taiwan where Kuroshio intrusion occurs.

\subsection{Water exchange in the inshore area induced by wind}

In the inshore area, the synoptic fluctuations of the TWC (Fig. 9b) caused by wind were generally strong in the alongshore direction and regionally important (along the latitudes 26.5 and $28^{\circ} \mathrm{N}$ ) in the cross-shore direction. The alongshore fluctuations showed that the TWC inshore branch occurred episodically. This episodic occurrence of the TWC agrees with the results from a previous study based on four mooring surveys off the Zhe-Min coast (Zeng et al., 2012). The mechanism of the episodic occurrence of the TWC was mainly associated with the winter monsoon, which agrees with the analysis of observational data by Huang et al. (2016). However, the overall magnitude of the TWC fluctuation, and its role in the cross-shore flux, is still not fully understood due to the short-term nature of the observational data.

We investigated the magnitude of TWC fluctuation, and its role in the water exchange, in the inshore area. Previous studies (Su and Pan, 1987; Zeng et al., 2012) showed that the TWC flows between the 50 and $100 \mathrm{~m}$ isobaths, whereas the ZMCC water dominates the coastal area west of the $50 \mathrm{~m}$ isobath in the surface layer. As mentioned when 


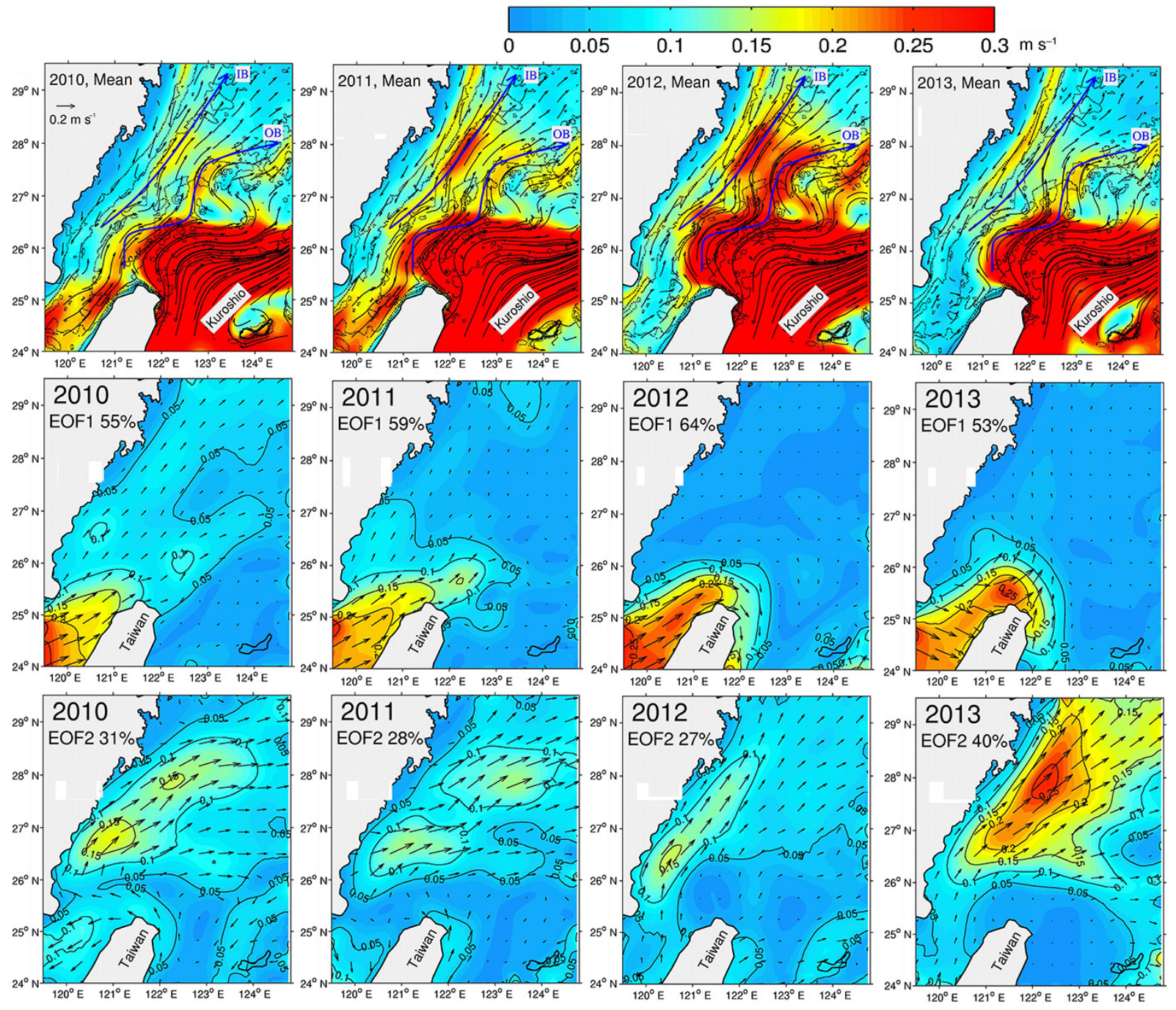

Figure 14. Mean currents (upper panels) and synoptic fluctuations (EOF1 in middle panels and EOF2 in bottom panels) in the winters of 2010-2013. The black arrows in the upper panels show the velocity $\left(\mathrm{m} \mathrm{s}^{-1}\right)$ in the layer of VMV with the color representing the current speed. The two blue arrows with label IB and OB represent the flow axes of the inshore branch and offshore branch, respectively. The black arrows in the middle panels and bottom panels represent the EOF components $\left(\mathrm{m} \mathrm{s}^{-1}\right)$ with their magnitude represented by color scales.

discussing Fig. 9d, the strongest TWC could reach the coastal area as close as the $30 \mathrm{~m}$ isobath, being stronger than those reported in the literature. Moreover, the area with large fluctuations spanned the area between the 30 and $100 \mathrm{~m}$ isobaths (Fig. 9b), indicating that water between the 30 and $100 \mathrm{~m}$ isobaths may be either ZMCC or TWC water.

The episodic occurrence of the TWC inshore branch is directly related to the relative importance of the southwestward ZMCC (Fig. 16, blue arrows) and the northeastward TWC (Fig. 16, red arrows). In this paper, only wind-induced synoptic fluctuations are considered, not short-term extreme storm events. When the winter monsoon (the northeasterly wind) prevails, the ZMCC occupies most of the inshore area and the TWC inshore branch weakens (Fig. 16a). On the contrary, the TWC inshore branch can intrude into the near-coast area under southwesterly wind conditions (Fig. 16b). The boundary between the coastal current and the TWC may shift from the $100 \mathrm{~m}$ isobaths to the $30 \mathrm{~m}$ isobath in the cross-shore direction, covering the entire area of the TWC inshore branch.

Our results further reveal that strong wind-induced crossshore fluctuations occur in the inshore area (Fig. 9f). This cross-shore fluctuation has a significant ecological impact because of the connected nutrient transport (Zhao and Guo, 2011). Ren et al. (2015) observed a cross-shore flux in the inshore area, which was triggered by the transition of northeasterly to southwesterly winds. Their observed features can be further interpreted with our result that wind-induced fluctuations can affect the cross-shore water transport in the inshore area. 


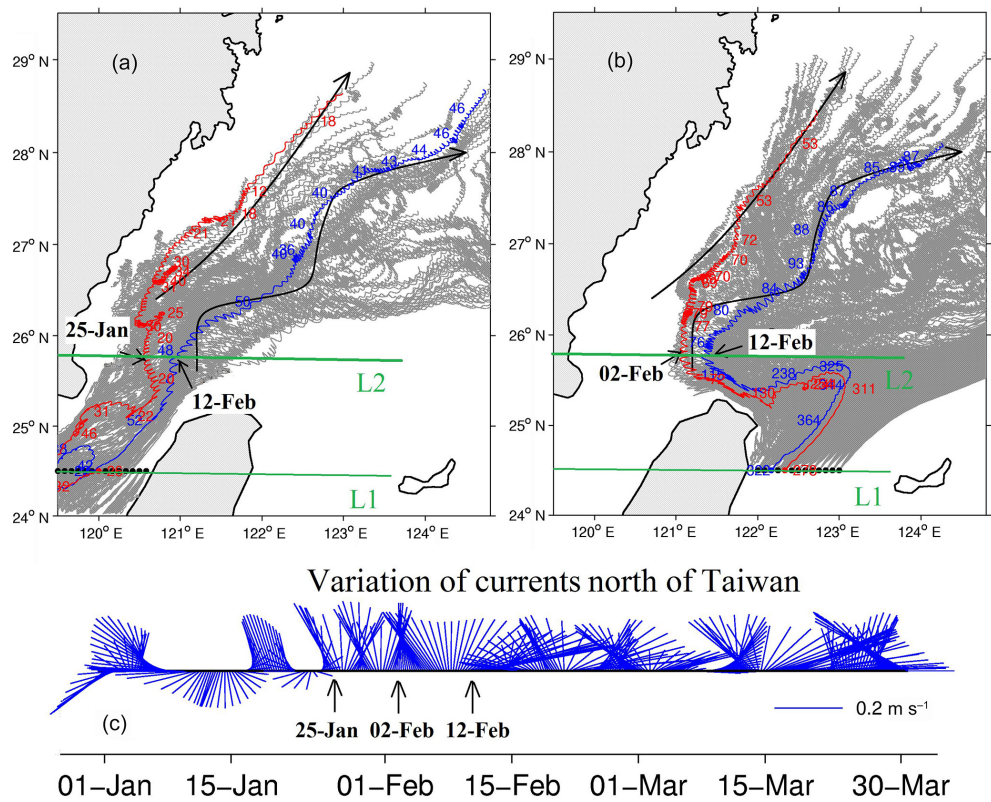

Figure 15. Traces of TSC water (a) and Kuroshio water (b) in winter, with the variation of surface currents north of Taiwan (c). The green lines L1 and L2 indicate the starting latitude of the tracers $\left(24.5^{\circ} \mathrm{N}\right)$ and the latitude which is representative for synoptic fluctuations north of Taiwan $\left(25.8^{\circ} \mathrm{N}\right)$, respectively. The black dots represent the release locations of tracers originated from line L1. The gray lines show the entire trajectories of the tracers. The red lines and blue lines are selected trajectories, which are close to the inshore branch and offshore branch, respectively. The dates show the times when selected tracers cross the latitude indicated by line L2. The numbers are the depths of the tracers, which are labeled at an interval of 6 days. The two black arrows represent the two TWC branches.
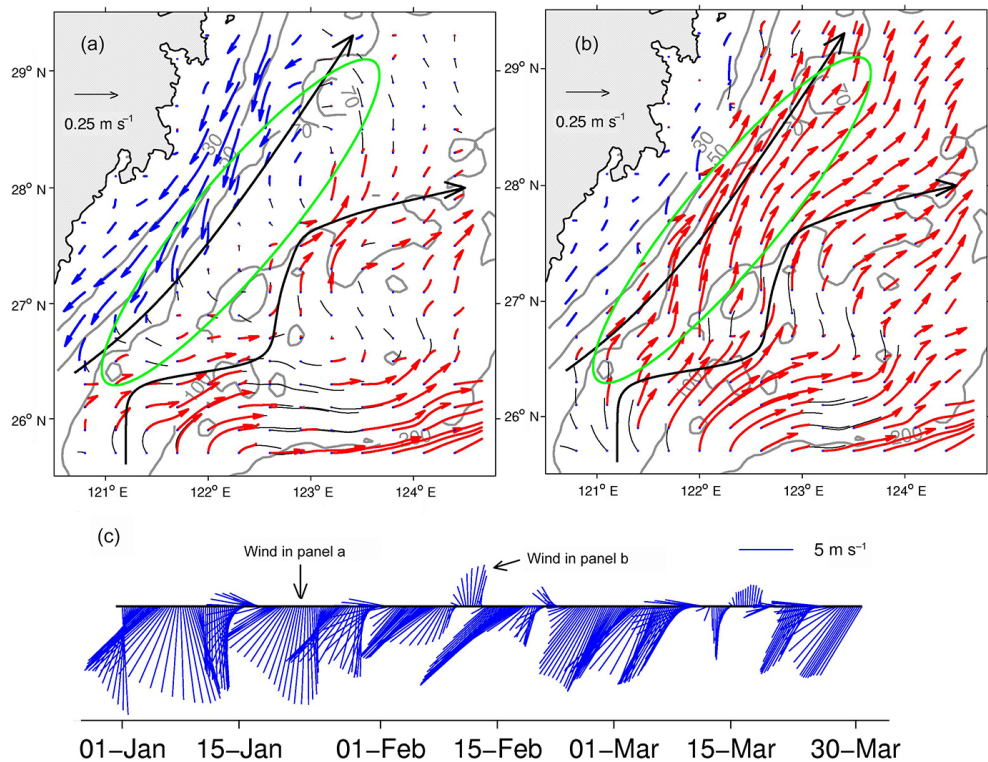

Figure 16. The VMV under the northerly wind (a) and southerly wind (b). (c) shows the variation of wind in winter. Blue vectors and red vectors show the southwestward coastal current and the northeastward TWC, respectively. Gray contours indicate the 30, 50, 70, and $100 \mathrm{~m}$ isobaths. The two black arrows represent the two TWC branches. The green ellipse indicates the inshore area with significant fluctuation.

The largest cross-shore fluctuations were located at the latitudes 26.5 and $28^{\circ} \mathrm{N}$ (Fig. 9f), which agreed well with the latitudes where the TWC offshore meanders occurred in the mean currents (Fig. 5a). Thus, the offshore transports were most significant along the latitudes 26.5 and $28^{\circ} \mathrm{N}$ according to both the mean currents and the synoptic fluctuations. The offshore transport may be associated with the offshorepenetrating fronts of coastal water in the ECS. Many remote 
sensing images (He et al., 2010; Bai et al., 2013) have exhibited offshore-penetrating fronts that crossed the $70 \mathrm{~m}$ isobath and played an important role in cross-shore material exchange, but the mechanisms of the offshore-penetrating fronts are still under debate. Yuan et al. (2005) pointed out that both downwelling- and upwelling-favorable winds are associated with the occurrence of the offshore-penetrating front. Ren et al. (2015) suggested that the penetrating front is generated by the transition of northeasterly to southwesterly winds. Wu (2015) suggested that the offshore-penetrating front is the response of buoyant coastal water to an alongisobath undulation of the ambient pycnocline, which is controlled by a temperature stratification of the water column. Our study offers a new interpretation; i.e., the penetrating front is generated through the wind-induced fluctuations and the TWC offshore meanders.

\section{Conclusions}

The FVCOM model was able to reproduce the wintertime TWC in 2009 reasonably well, as shown by a validation in terms of the overall structure of the surface mean currents, the ECS boundary fluxes and data from four mooring stations. The validation showed that the simulated TWC was comparable to the observed results, not only in terms of the mean currents but also in terms of the synoptic fluctuations.

The wintertime TWC showed two branches: one inshore and another offshore. The inshore branch covered an area between the 30 and $100 \mathrm{~m}$ isobaths and flowed northeastward via a straight route. The offshore branch was located between the 100 and $200 \mathrm{~m}$ isobaths and showed two prominent meanders. It was shown that the Coriolis force was nearly balanced by the pressure gradient in both branches, indicating the dominant role of the geostrophic balance for the mean current in both branches.

Two regions with significant synoptic fluctuations, north of Taiwan and the inshore area, were investigated using the EOF method. The first two leading modes explained $91 \%$ of the total variance. EOF1 showed that fluctuations occurred in the cross-shore direction south of $26^{\circ} \mathrm{N}$. These fluctuations were mainly associated with variation of the TSC flux. EOF2 showed significant fluctuation between the 30 and $100 \mathrm{~m}$ isobaths. These fluctuations caused the episodic existence of the TWC inshore branch in the alongshore direction and crossshore fluctuations mainly at latitudes 26.5 and $28^{\circ} \mathrm{N}$, which were mainly associated with the variation of wind speed.

We also studied the different dynamic reasons for the fluctuations in the two regions. In the area north of Taiwan, the TSC and Kuroshio converged to initiate the TWC. A barotropic pressure anomaly was generated by TSC intrusion from the Taiwan Strait causing a barotropic pressure gradient in the alongshore direction; this explains why the synoptic fluctuations in this area occurred in the cross-shore direction. Additionally, the wind had a strong effect on the synoptic fluctuations in the inshore area. The northeasterly monsoon enhanced the southwestward ZMCC and replaced the TWC in the inshore area. This situation is reversed during the southwesterly wind.

The synoptic fluctuations north of Taiwan and in the inshore area are important for both the alongshore and crossshore transports. Due to the fluctuation north of Taiwan, the mixed water of the TSC and the Kuroshio was transported to both the inshore area and the offshore area, whereas most Taiwan Strait water was transported to the offshore area in winter. The inshore fluctuation not only caused an episodic occurrence of the TWC in the alongshore direction, which affected the alongshore transport of ZMCC water and TWC water between the 30 and $100 \mathrm{~m}$ isobaths, but also impacted the cross-shore transports along latitudes 26.5 and $28^{\circ} \mathrm{N}$.

\section{Data availability}

The observed and simulated currents data in the subsurface layer of the research area are available at http://pan.baidu. com/s/1i5jwUpv.

Competing interests. The authors declare that they have no conflict of interest.

Acknowledgements. The authors sincerely thank John M. Huthnance and the three anonymous reviewers for insightful suggestions that improved this manuscript. This study was jointly supported by the Sino-German cooperation in ocean and polar research under the grant BMBF-03F0701A (CLIFLUX), the National Natural Science Foundation of China (U1609201, 41621064, 41306025), the grant from the scientific research fund of the Second Institute of Oceanography, SOA (QNYC201603), and the project of State Key Laboratory of Satellite Ocean Environment Dynamics, the Second Institute of Oceanography (SOEDZZ1512).

Edited by: J. M. Huthnance

Reviewed by: three anonymous referees

\section{References}

Bai, Y., Pan, D., Cai, W. J., He, X., Wang, D., Tao, B., and Zhu, Q.: Remote sensing of salinity from satellite-derived CDOM in the Changjiang River dominated East China Sea, J. Geophys. Res.Oceans, 118, 227-243, 2013.

Bleck, R.: An oceanic general circulation model framed in hybrid isopycnic-Cartesian coordinates, Ocean Model., 37, 55-88, 2002.

Brink, K. H.: Costal trapped waves and wind-induced currents over the continental shelf, Ann. Rev. Fluid Mech., 23, 389-412, 1991.

Carnes, M. R.: Description and evaluation of GDEM-V3.0, NRL Rep. NRL/MR/7330-09-9165, Nav. Res. Lab., Washington, D.C., 2009. 
Chen, C., Beardsley, R. C., Limeburner, R., and Kim, K.: Comparison of winter and summer hydrographic observations in the Yellow and East China seas and adjacent Kuroshio during 1986, Cont. Shelf Res., 14, 909-929, 1994.

Chen, C., Liu, H., and Beardsley, R. C.: An unstructured, finitevolume, three-dimensional, primitive equation ocean model: application to coastal ocean and estuaries, J. Atmos. Ocean. Tech., 20, 159-186, 2003.

Chen, C., Xue, P., Ding, P., Beardsley, R. C., Xu, Q., Mao, X., Gao, G., Qi, J., Li, C., Lin, H., Cowles, G., and Shi, M.: Physical mechanisms for the offshore detachment of Changjiang Diluted Water in the East China Sea, J. Geophys. Res., 113, C02002, doi:10.1029/2006JC003994, 2008.

Chen, C. T. A. and Wang, S. L.: Carbon, alkalinity and nutrient budget on the East China Sea continental shelf, J. Geophys. Res.Oceans, 104, 20675-20686, 1999.

Chuang, W. S. and Liang, W. D.: Seasonal variability of intrusion of the Kuroshio water across the continental shelf northeast of Taiwan, J. Oceanogr., 50, 531-542, 1994.

Cui, M., Hu, D., and Wu, L.: Seasonal and intraseasonal variations of the surface Taiwan Warm Current, Chin. J. Oceanol. Limnol., 22, 271-277, 2004.

Dee, D. P., Uppala, S. M., Simmons, A. J., Berrisford, P., Poli, P., Kobayashi, S., Andrae, U., Balmaseda, M. A., Balsamo, G., Bauer, P., Bechtold, P., Beljaars, A. C. M., van de Berg, L., Bidlot, J., Bormann, N., Delsol, C., Dragani, R., Fuentes, M., Geer, A. J., Haimberger, L., Healy, S. B., Hersbach, H., Hólm, E. V., Isaksen, L., Kållberg, P., Köhler, M., Matricardi, M., McNally, A. P., Monge-Sanz, B. M., Morcrette, J.-J., Park, B.-K., Peubey, C., de Rosnay, P., Tavolato, C., Thépaut, J.-N., and Vitart, F.: The ERA-Interim reanalysis: configuration and performance of the data assimilation system, Q. J. Roy. Meteorol. Soc., 137, 553597, doi:10.1002/qj.828, 2011

Egbert, G. D. and Erofeeva, S. Y.: Efficient inverse modeling of barotropic ocean tides, J. Atmos. Ocean. Tech., 19, 183-204, 2002.

Egbert, G. D., Bennett, A., and Foreman, M.: TOPEX/Poseidon tides estimated using a global inverse model, J. Geophys. Res., 99, 24821-24852, doi:10.1029/94JC01894, 1994.

Emery, W. J. and Thomson, R. E.: Data analysis methods in physical oceanography, Second and revised version, Elsevier Science B.V., Ameterdam, the Netherlands, 658 pp., 2001.

Fang, G., Zhao, B., and Zhu, Y.: Water volume transport through the Taiwan Strait and the continental shelf of the East China Sea measured with current meters, in: Oceanography of Asian Marginal Seas, edited by: Takano, K., Elsevier, New York, 345358, doi:10.1016/S0422-9894(08)70107-7, 1991.

Feng, M., Mitsudera, H., and Yoshikawa, Y.: Structure and Variability of the Kuroshio Current in Tokara Strait, J. Phys. Oceanogr., 30, 2257-2276, 2000.

Godin, G.: The Analysis of Tides, University of Toronto Press, Toronto, 264 pp., 1972.

Grachev, A. A., Andreas, E. L., Fairall, C. W., Guest, P. S., and Persson, P. O. G.: The critical Richardson number and limits of applicability of local similarity theory in the stable boundary layer, Bound.-Lay. Meteorol., 147, 51-82, 2013.

Guan, B. and Fang, G.: Winter counter-wind currents off the southeastern China coast: A review, J. Oceanogr., 62, 1-24, 2006.
Guan, B. and Mao, H.: A note on circulation of the East China Sea, Chin. J. Oceanol. Limnol., 1, 5-16, 1982.

Guan, B. X.: A sketch of the current system of the East China Sea, in: Collected Papers of the Continental Shelf of the East China Sea, Inst. of Oceanol., Chin. Acad. of Sci., Qingdao, China, 126133, 1978.

Guo, X. Y., Hukuda, H., Miyazawa, Y., and Yamagata, T.: A triply nested ocean model for simulating the Kuroshio - Roles of horizontal resolution on JEBAR, J. Phys. Oceanogr., 33, 146-169, 2003.

Guo, X. Y., Miyazawa, Y., and Yamagata, T.: The Kuroshio onshore intrusion along the shelf break of the East China Sea: The origin of the Tsushima Warm Current, J. Phys. Oceanogr., 36, 22052231, doi:10.1175/JPO2976.1, 2006.

He, L., Li, Y., Zhou, H., and Yuan, D.: Variability of cross-shelf penetrating fronts in the East China Sea, Deep-Sea Res., 57, 18201826, 2010.

Hong, H., Chai, F., Zhang, C., Huang, B., Jiang, Y., and Hu, J.: An overview of physical and biogeochemical processes and ecosystem dynamics in the Taiwan Strait, Cont. Shelf Res., 31, 3-12, 2011.

Hsin, Y. C., Qiu, B., Chiang, T. L., and Wu, C. R.: Seasonal to interannual variations in the intensity and central position of the surface Kuroshio east of Taiwan, J. Geophys. Res.-Oceans, 118, 4305-4316, 2013.

Hu, J., Kawamura, H., Li, C., Hong, H., and Jiang, Y.: Review on current and seawater volume transport through the Taiwan Strait, J. Oceanogr., 66, 591-610, 2010.

Huang, D., Zeng, D., Ni, X., Zhang, T., Xuan, J., Zhou, F., Li, J., and He, S.: Alongshore and cross-shore circulations and their response to winter monsoon in the western East China Sea, DeepSea Res. Pt. II, 124, 6-18, doi:10.1016/j.dsr2.2015.01.001, 2016.

Hung, J. J., Chen, C. H., Gong, G. C., Sheu, D. D., and Shiah, F. K.: Distributions, stoichiometric patterns and cross-shelf exports of dissolved organic matter in the East China Sea, Deep-Sea Res. Pt. II, 50, 1127-1145, 2003.

Huthnance, J. M., Mysak, L. A., and Wang, D. P.: Coastal trapped waves, in: Baroclinic Processes on Continental Shelves, Coastal and Estuarine Sciences, edited by: Mooers, C. N. K., American Geophysical Union, Washington, D.C., 1-18, 1986.

Huyer, A.: Shelf circulation, in: The Sea, Vol. 9: Ocean Engineering Science, edited by: Mehaute, B. L. and Hames, D. M., Wiley, New York, 423-466, 1990.

Isobe, A.: Recent advances in ocean-circulation research on the Yellow Sea and East China Sea shelves, J. Oceanogr., 64, 569-584, doi:10.1007/s10872-008-0048-7, 2008.

Johns, W. E., Lee, T. N., Zhang, D., Zantopp, R., Liu, C. T., and Yang, Y.: The Kuroshio east of Taiwan: Moored transport observations from the WOCE PCM-1 array, J. Phys. Oceanogr., 31, 1031-1053, 2001.

Ledwell, J. R., Watson, A. J., and Law, C. S.: Mixing of a tracer in the pycnocline, J. Geophys. Res., 103, 21499-21529, doi:10.1029/98JC01738, 1998.

Lee, J. S. and Matsuno, T.: Intrusion of Kuroshio water onto the continental shelf of the East China Sea, J. Oceanogr., 63, 309325, 2007.

Liu, C., Wang, F., Chen, X., and VonStorch, J. S.: Interannual variability of the Kuroshio onshore intrusion along the East China Sea shelf break: Effect of the Kuroshio vol- 
ume transport, J. Geophys. Res.-Oceans, 119, 6190-6209, doi:10.1002/2013JC009653, 2014.

Liu, T., Xu, J., He, Y., Lü, H., Yao, Y., and Cai, S.: Numerical simulation of the Kuroshio intrusion into the South China Sea by a passive tracer, Acta Oceanol. Sin., 35, 1-12, doi:10.1007/s13131-016-0930-x, 2016.

Liu, X., Dong, C., Chen, D., and Su, J.: The pattern and variability of winter Kuroshio intrusion northeast of Taiwan, J. Geophys. Res.-Oceans, 119, 5380-5394, doi:10.1002/2014JC009879, 2014.

Mellor, G. L. and Durbin, P. A.: The structure and dynamics of the ocean surface mixed layer, J. Phys. Oceanogr., 5, 718-728, 1975.

Oey, L. Y., Hsin, Y. C., and Wu, C. R.: Why does the Kuroshio northeast of Taiwan shift shelfward in winter?, Ocean Dynam., 60, 413-426, 2010.

Qiu, B. and Imasato, N.: A numerical study on the formation of the Kuroshio countercurrent and the Kuroshio Branch Current in the East China Sea, Cont. Shelf Res., 10, 165-184, doi:10.1016/0278-4343(90)90028-K, 1990.

Ren, J. L., Xuan, J., Wang, Z. W., Huang, D., and Zhang, J.: Cross-shelf transport of terrestrial $\mathrm{Al}$ enhanced by the transition of northeasterly to southwesterly monsoon wind over the East China Sea, J. Geophys. Res.-Oceans, 120, 5054-5073, doi:10.1002/2014JC010655, 2015.

Richardson, H., Basu, S., and Holtslag, A. A. M.: Improving stable boundary-layer height estimation using a stability-dependent critical bulk Richardson number, Bound.-Lay. Meteorol., 148, 93-109, 2013.

Smith, W. H. F. and Sandwell, D. T.: Global sea floor topography from satellite altimetry and ship depth soundings, Science, 277, 1956-1962, 1997.

Su, J. L. and Pan, Y. Q.: On the shelf circulation north of Taiwan, Acta Oceanol. Sin., 6, 1-20, 1987.

Su, J. L., Pan, Y. Q., and Liang, X. S.: Kuroshio intrusion and Taiwan warm current, Oceanology of China Seas, Springer Netherlands, 59-70, 1994.

Takahashi, D. and Morimoto, A.: Mean field and annual variation of surface flow in the East China Sea as revealed by combining satellite altimeter and drifter data, Prog. Oceanogr., 111, 125139, doi:10.1016/j.pocean.2013.01.007, 2013.

Teague, W., Jacobs, G., Ko, D., Tang, T., Chang, K. I., and Suk, M. S.: Connectivity of the Taiwan, Cheju, and Korea straits, Cont. Shelf Res., 23, 63-77, 2003.

Wang, Y., Jan, S., and Wang, D.: Transports and tidal current estimates in the Taiwan Strait from shipboard ADCP observations (1999-2001), Estuar. Coast. Shelf Sci., 57, 193-199, 2003.

Wei, Y., Huang, D., and Zhu, X. H.: Interannual to decadal variability of the Kuroshio Current in the east china sea from 1955 to 2010 as indicated by in-situ hydrographic data, J. Oceanogr., 69, 571-589, 2013.
Wu, C. R. and Hsin, Y. C.: Volume transport through the Taiwan Strait: a numerical study, Terr. Atmos. Ocean. Sci., 16, 377-391, 2005.

$\mathrm{Wu}, \mathrm{H} .:$ Cross-shelf penetrating fronts: A response of buoyant coastal water to ambient pycnocline undulation, J. Geophys. Res., 120, 5101-5119, doi:10.1002/2014JC010686, 2015.

Xuan, J., Huang, D., Zhou, F., Zhu, X. H., and Fan, X.: The role of wind on the detachment of low salinity water in the Changjiang Bank in summer, J. Geophys. Res.-Oceans, 117, C10004, doi:10.1029/2012JC008121, 2012a.

Xuan, J., Zhou, F., Huang, D., Zhu, X. H., Xing, C., and Fan, X.: Modelling the timing of major spring bloom events in the central Yellow Sea, Estuar. Coast. Shelf Sci., 113, 283-292, 2012b.

Xuan, J., Yang, Z., Huang, D., Wang, T., and Zhou, F.: Tidal residual current and its role in the mean flow on the Changjiang Bank, J. Mar. Syst., 154, 66-81, doi:10.1016/j.jmarsys.2015.04.005, 2016.

Yang, D., Yin, B., Liu, Z., and Feng, X.: Numerical study of the ocean circulation on the East China Sea shelf and a Kuroshio bottom branch northeast of Taiwan in summer, J. Geophys. Res.Oceans, 116, C05015, doi:10.1029/2010JC006777, 2011.

Yang, D., Yin, B., Liu, Z., Bai, T., Qi, J., and Chen, H.: Numerical study on the pattern and origins of Kuroshio branches in the bottom water of southern East China Sea in summer, J. Geophys. Res.-Oceans, 117, C02014, doi:10.1029/2011JC007528, 2012.

$\mathrm{Yu}, \mathrm{L}$. and Weller, R. A.: Objectively Analyzed air-sea heat Fluxes (OAFlux) for the global oceans, B. Am. Meteorol. Soc., 88, 527-539, 2007.

Yuan, D., Qiao, F., and Su, J.: Cross-shelf penetrating fronts off the southeast coast of China observed by MODIS, Geophys. Res. Lett., 32, L19603, doi:10.1029/2005GL023815, 2005.

Zeng, D. Y., Ni, X., and Huang, D.: Temporal and spatial variability of the Zhe-Min Coastal Current and the Taiwan Warm Current in winter in the southern Zhejiang coastal sea, Sci. Sin. Terrae., 42, 1123-1134, 2012.

Zhao, L. and Guo, X.: Influence of cross-shelf water transport on nutrients and phytoplankton in the East China Sea: A model study, Ocean Sci., 7, 27-43, doi:10.5194/os-7-27-2011, 2011.

Zhou, F., Xue, H., Huang, D., Xuan, J., Ni, X., Xiu, P., and Hao, Q.: Cross shelf exchange in the shelf of the East China Sea, J. Geophys. Res.-Oceans, 120, 1545-1572, doi:10.1002/2014JC010567, 2015.

Zhu, J., Chen, C., Ding, P., Li, C., and Lin, H.: Does the Taiwan Warm Current exist in winter?, Geophys. Res. Lett., 31, L12302, doi:10.1029/2004GL019997, 2004. 